\title{
Ecological relationships, thresholds and time-lags determining phytoplankton community dynamics of Lake Kinneret, Israel elucidated by evolutionary computation and wavelets
}

\author{
Friedrich Recknagel ${ }^{\mathrm{a}, *}$, Ilia Ostrovsky ${ }^{\mathrm{b}}$, Hongqing Cao $^{\mathrm{a}}$, Tamar Zohary ${ }^{\mathrm{b}}$, Xiaoqing Zhang $^{\mathrm{c}}$ \\ a University of Adelaide, School of Earth and Environmental Sciences, Adelaide 5005, Australia \\ ${ }^{\mathrm{b}}$ Israel Oceanographic and Limnological Research, Kinneret Limnological Laboratory, Migdal 14950, Israel \\ ${ }^{\mathrm{c}}$ Research Center for Eco-Environmental Science, Chinese Academy of Sciences, Beijing 100085, China
}

\section{A R T I C L E I N F O}

\section{Article history:}

Received 27 August 2012

Received in revised form 8 January 2013

Accepted 2 February 2013

\section{Keywords:}

Lake Kinneret

Phytoplankton community

Ecological relationships

Ecological thresholds

Time lags

Forecasting

Inductive reasoning

Evolutionary computation

Sensitivity analysis

Wavelet analysis

\begin{abstract}
A B S T R A C T
The hybrid evolutionary algorithm (HEA) was implemented to model and analyze population dynamics of the different phytoplankton phyla (chlorophyta, bacillariophyta, cyanophyta and dinophyta) in relation to physical, chemical, and biological determinants and their combinations in a large lake. Biweekly measurements over a 12-year period were used as input. The validation of models obtained with HEA showed the best results for bacillariophyta and dinophyta resulting in coefficients of determination $\left(r^{2}\right)$ between the modeled and measured data of 0.54-0.79 and 0.29-0.76 for these phyla, respectively, suggesting good predictability of their dynamics. The lowest adequacy of HEA models was found for cyanophyta ( $r^{2}$ of $0.28-0.46$ ). Models that combined physical, chemical and biological inputs scored highest, whilst zooplankton-based models scored lowest in all experiments and indicated that top-down control of algal biomass could have only secondary effect. The input sensitivity analysis was used for testing the best phytoplankton models with threshold values determining high or low algal biomass and inhibitory-excitatory effects of specific parameters. Wavelets were tested to analyze two extreme cases of dinophyta dynamics in years of its exceptionally high and low developments to gain insights into lag times between the exert of key factor and algae response. Lag times extracted from daily interpolated data of highly correlated inputs of dinophyta in 1998 varied between 2 and 4 days.
\end{abstract}

Crown Copyright @ 2013 Published by Elsevier B.V. All rights reserved.

\section{Introduction}

Thresholds of nonlinear ecological relationships can be driven by factors inducing momentary events, e.g. environmental conditions favoring the emergence of algal populations from resting cells. Alternatively thresholds may be built up by complex cumulative processes such as eutrophication, and cause long-lasting community changes and/or ecosystem regime shifts. Lags between the time of factor exertion and community/ecosystem response also conceal causative relationships, and make their analyses by traditional statistical models complex. Knowing the nature of ecological relationships, discovering hidden associations masked by thresholds and time lags is crucial for understanding the functioning of aquatic ecosystems, and - as such - prerequisite for informed ecosystem management and monitoring.

Great efforts are undertaken to explain ecological thresholds in theoretical terms (e.g. Rinaldi and Scheffer, 2000; Scheffer and

\footnotetext{
* Corresponding author. Tel.: +61 433500089.

E-mail address: friedrich.recknagel@adelaide.edu.au (F. Recknagel).
}

Jeppesen, 2007), but little progress has been achieved by quantitative analysis of relevant data (e.g. Toms and Lesperance, 2003; Carpenter and Lathrop, 2008; Sonderegger et al., 2009). As stated by Sonderegger et al. (2009) only multivariate nonlinear methods such as evolutionary computation have the capacity to successfully identify and quantify ecological thresholds in data.

Traditionally applied Fourier analysis for spectral analysis of plankton community data (e.g. Vasseur and Gaedke, 2007) assumes that the statistical properties of the time series are stationary. However, population dynamics typically have non-stationary features that wavelets can match by estimating its spectral characteristics as a function of time (Cazelles et al., 2008).

This research aimed to test evolutionary computation and wavelets to corroborate ecological relationships that determine dynamics of the phytoplankton community in one of the bestmonitored freshwater ecosystems - Lake Kinneret (Israel).

Evolutionary computation (EC) (Holland, 1975) captures patterns in data and represents patterns by multivariate nonlinear rules using cyclically performing genetic operations such as "crossover", "mutations" and "reproduction". It therefore has the capacity to evolve the 'fittest' (best-matching) mathematical formulations 


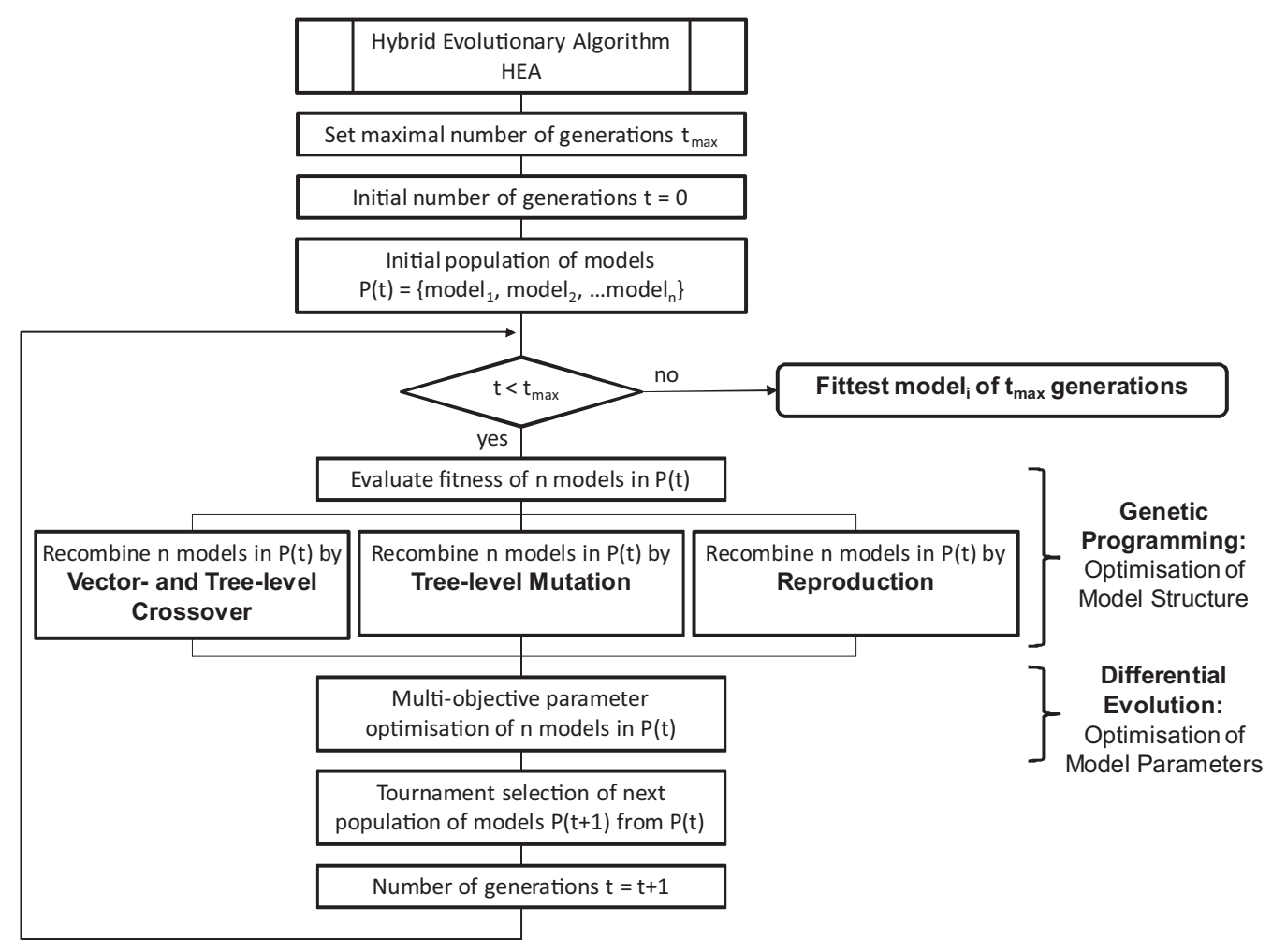

Fig. 1. Design and functioning of the hybrid evolutionary algorithm HEA.

for relationships between targeted input and output variables that suit both elucidation and prediction.

The wavelet analysis overcomes limitations of the Fourier analysis by providing an approach to the spectrum analysis for non-stationary time series as characteristic for ecological data.

Twelve years of limnological data collected between 1988 and 1999 at a central station of Lake Kinneret were used to model seasonal and inter-annual dynamics of the phytoplankton phyla: chlorophyta, bacillariophyta, dinophyta and cyanophyta by EC.

Wavelets were applied to daily interpolated data from April to May of the years 1997 and 1998 in order to compare time lags between dinophyta and selected input variables.

\section{Materials and methods}

\subsection{Limnological data of Lake Kinneret}

Lake Kinneret (Sea of Galilee) is a large meso-eutrophic monomictic lake located in northern part of Israel. It covers an area of $\sim 170 \mathrm{~km}^{2}$, and its maximum depth is of $39-44 \mathrm{~m}$ depending of water level. The water quality of the lake is of great importance since it supplies about 50\% of Israel's freshwater. The lake is stratified from March-April to December-January. Lake Kinneret receives most of its water and supplied by allochthonous nutrients from the northern Jordan River. Due to seasonal changes in rainfall and water consumption from Lake Kinneret, its water level altered from -212.9 to $-208.9 \mathrm{~m}$ above sea level over the analyzed period (1988 and 1999). The lake phytoplankton assemblage was reported by Pollingher (1986) to have a typical annual succession pattern that was repeated from year to year. Its characteristic feature was an intense spring bloom of the dinoflagellate Peridinium gatunense. However, in the mid 1990s the Kinneret phytoplankton underwent a major change, resembling a regime shift (Zohary, 2004). Since then $P$. gatunense blooms developed only after high-inflow winters
Table 1

Water quality variables measured at a central site of lake Kinneret from 1988 to 1999.

\begin{tabular}{|c|c|c|}
\hline Water quality variables & Units & Mean \pm SD \\
\hline \multicolumn{3}{|l|}{ Physical parameters } \\
\hline WT (mean surface water temperature) & ${ }^{\circ} \mathrm{C}$ & $22.3 \pm 5.1$ \\
\hline $\begin{array}{l}\text { Depth_Epi (depth of the surface water } \\
\text { layer during thermal stratification; it } \\
\text { equals depth of lake during lake's } \\
\text { turn-over) }\end{array}$ & $\mathrm{m}$ & $21.4 \pm 12.5$ \\
\hline $\begin{array}{l}\text { WL_Change (seasonal change of the } \\
\text { lake water level) }\end{array}$ & $\mathrm{m}$ & $1.4 \pm 1.3$ \\
\hline $\begin{array}{l}\text { Secchi depth (depth of water } \\
\text { transparency) }\end{array}$ & $\mathrm{m}$ & $3.4 \pm 0.8$ \\
\hline \multicolumn{3}{|l|}{ Chemical parameters } \\
\hline $\mathrm{pH}$ & & $8.6 \pm 0.3$ \\
\hline Alkalinity & $\mathrm{mg} \mathrm{CaCO}_{3} / \mathrm{L}$ & $115.95 \pm 11.9$ \\
\hline DO (dissolved oxygen) & $\mathrm{mg} / \mathrm{L}$ & $9.25 \pm 2.14$ \\
\hline COND (electrical conductivity) & $\mu \mathrm{S} / \mathrm{cm}$ & $445.5 \pm 43.3$ \\
\hline $\begin{array}{l}\mathrm{NO}_{3} \text { _inflow (nitrate load from Jordan } \\
\text { River) }\end{array}$ & t/day & $2.97 \pm 4.92$ \\
\hline $\mathrm{NO}_{3}$ (nitrate) & $\mathrm{mg} / \mathrm{L}$ & $0.11 \pm 0.15$ \\
\hline TN (total nitrogen) & $\mathrm{mg} / \mathrm{L}$ & $0.57 \pm 0.26$ \\
\hline $\begin{array}{l}\mathrm{PO}_{4} \text { inflow (phosphate load from } \\
\text { Jordan River) }\end{array}$ & t/day & $0.04 \pm 0.05$ \\
\hline $\mathrm{PO}_{4}$ (phosphate) & $\mathrm{mg} / \mathrm{L}$ & $0.002 \pm 0.001$ \\
\hline TP (total phosphorus) & $\mathrm{mg} / \mathrm{L}$ & $0.02 \pm 0.01$ \\
\hline TN_TP (TN:TP ratio) & & $30.1 \pm 12.1$ \\
\hline \multicolumn{3}{|l|}{ Biological parameters } \\
\hline Chlorophyta & $\mathrm{g} / \mathrm{m}^{2}$ & $11.6 \pm 9.5$ \\
\hline Cyanophyta & $\mathrm{g} / \mathrm{m}^{2}$ & $4.2 \pm 9.3$ \\
\hline Dinophyta & $\mathrm{g} / \mathrm{m}^{2}$ & $57.9 \pm 86.2$ \\
\hline Bacillariophyta & $\mathrm{g} / \mathrm{m}^{2}$ & $12.1 \pm 32.5$ \\
\hline Copepoda & ind $/ \mathrm{L}$ & $112.1 \pm 84.8$ \\
\hline Cladocera & ind $/ \mathrm{L}$ & $46.6 \pm 35$ \\
\hline Rotifera & ind $/ \mathrm{L}$ & $66.9 \pm 109.6$ \\
\hline
\end{tabular}




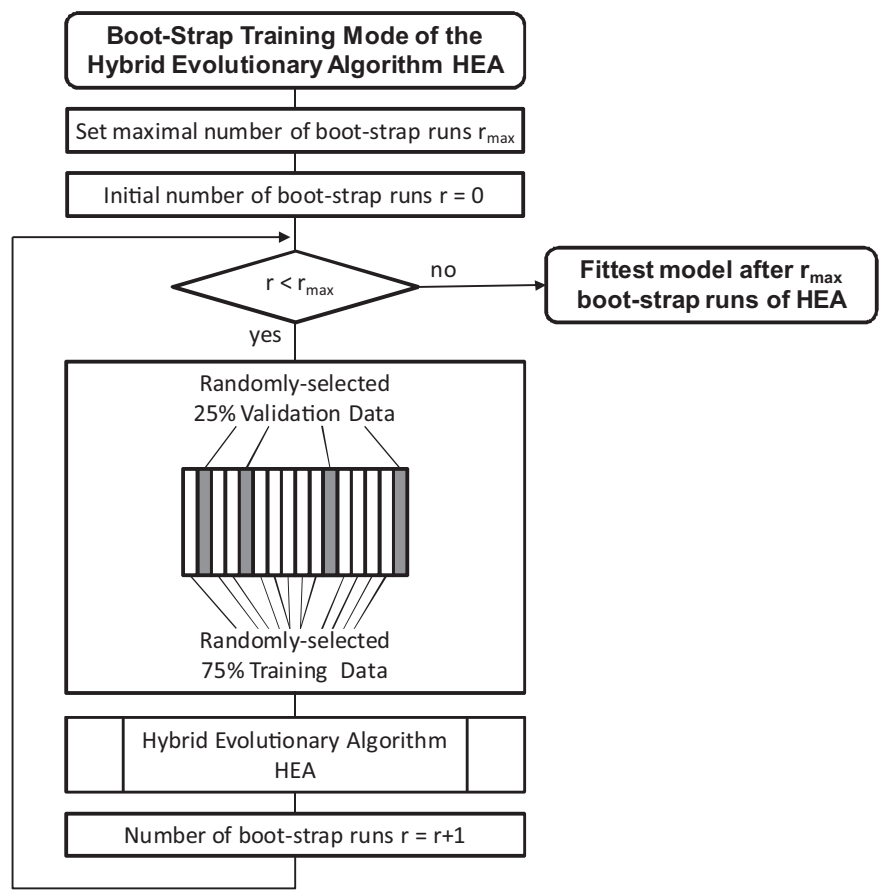

Fig. 2. Scheme of boot-strap training applied to the hybrid evolutionary algorithm HEA.
(Zohary and Ostrovsky, 2011); a bloom failed to develop in some years. Other deviations from the previous typical annual pattern included higher summer phytoplankton biomass with replacement of the species assemblage of mostly nanoplanktonic; new appearance and establishment of toxin-producing, nitrogen-fixing cyanobacteria in summer; and an increase in the absolute biomass and proportion of cyanobacteria to total biomass (Ostrovsky et al., 2013).

The lake has been monitored regularly since 1969 on weekly and biweekly bases. In this paper we analyzed the dynamics of major algal phyla between 1988 and 1999 in relation to ecosystem variables (Table 1). Data on biological, chemical and physical parameters of Lake Kinneret were collected by the Kinneret Limnological Laboratory at the central station A; data on chemical and hydrological parameters of the Jordan River (the main source of nutrient load to Lake Kinneret) were monitored at station $\mathrm{H}$ (Huri Bridge) by the Mekorot Water Company. In Lake Kinneret most of the variables measured at several standard depths were averaged over the upper 10-m layer where most of the algal community develops. Monitoring of water temperature and estimation of epilimnion depth is described by Rimmer et al. (2011). Chemical parameters in Lake Kinneret and Jordan River were measured using standard procedure (APHA, 1998; Nishri, 2011). Phytoplankton and zooplankton abundances were estimated for the upper oxygenated layer and described by Zohary (2004) and Gophen (1972), respectively. Phytoplankton was categorized based on the following phyla: cyanophyta, dinophyta, chlorophyta, and, bacillariophyta (diatoms). Zooplankton was categorized using systematic affiliation (copepoda, cladocera and rotifera) as well as

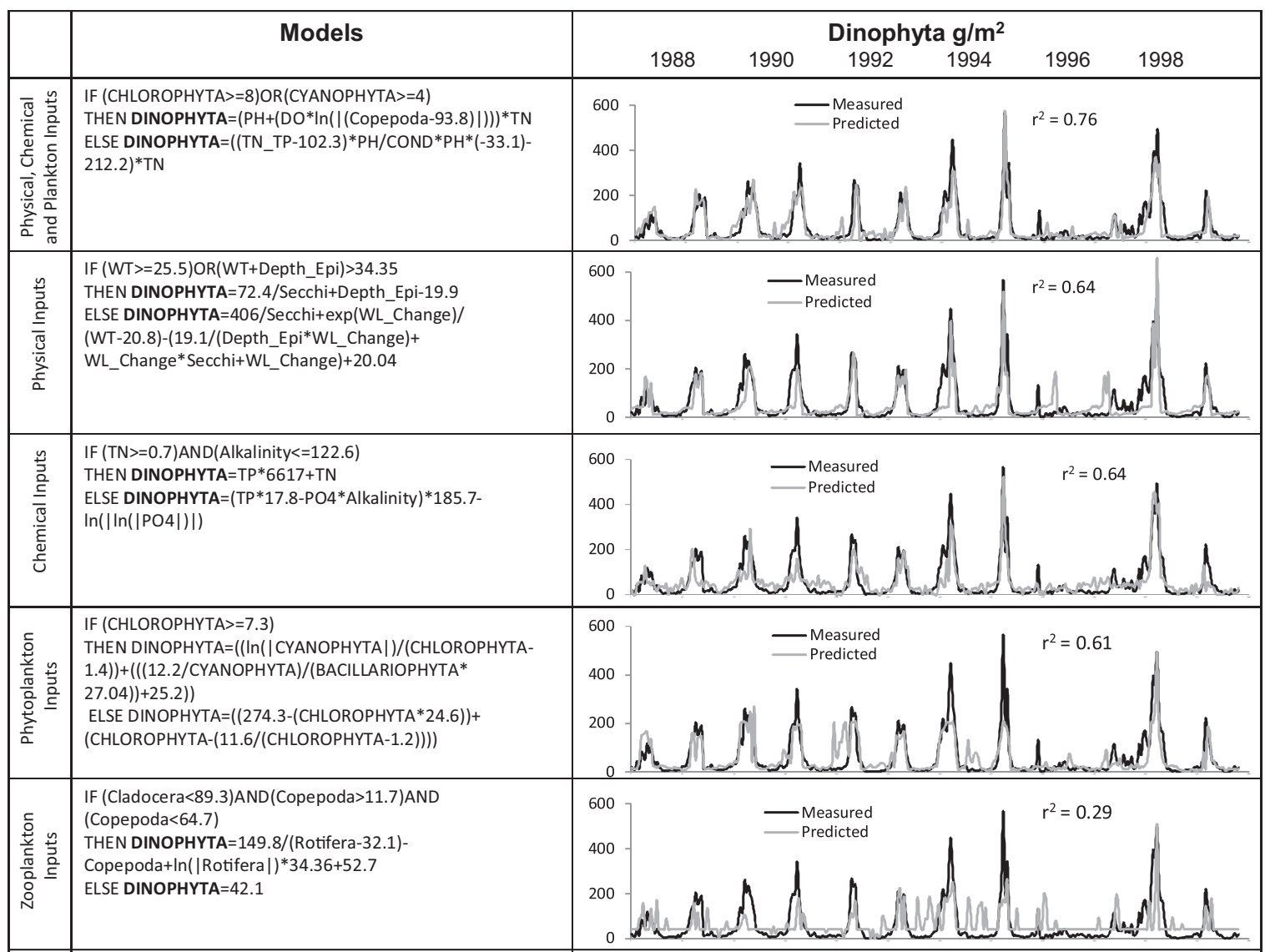

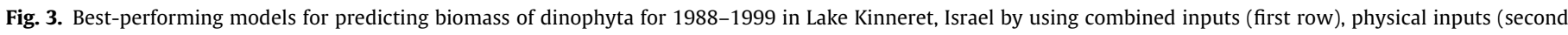
row), chemical inputs (third row), phytoplankton inputs (fourth row) and zooplankton inputs (fifths row). 


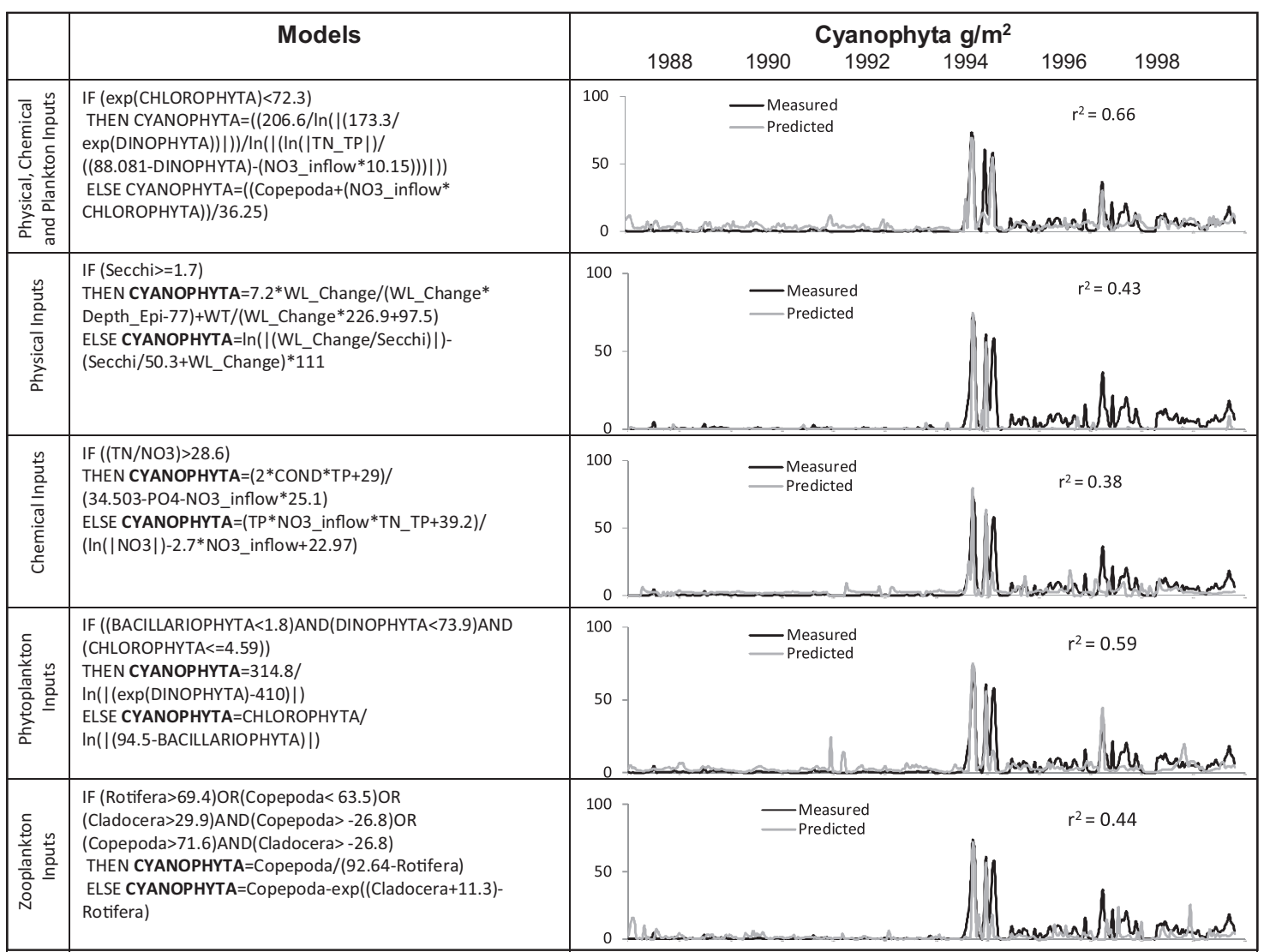

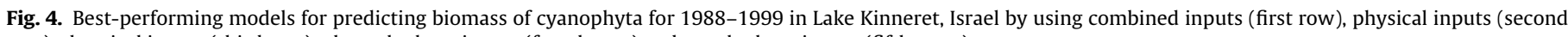
row), chemical inputs (third row), phytoplankton inputs (fourth row) and zooplankton inputs (fifths row).

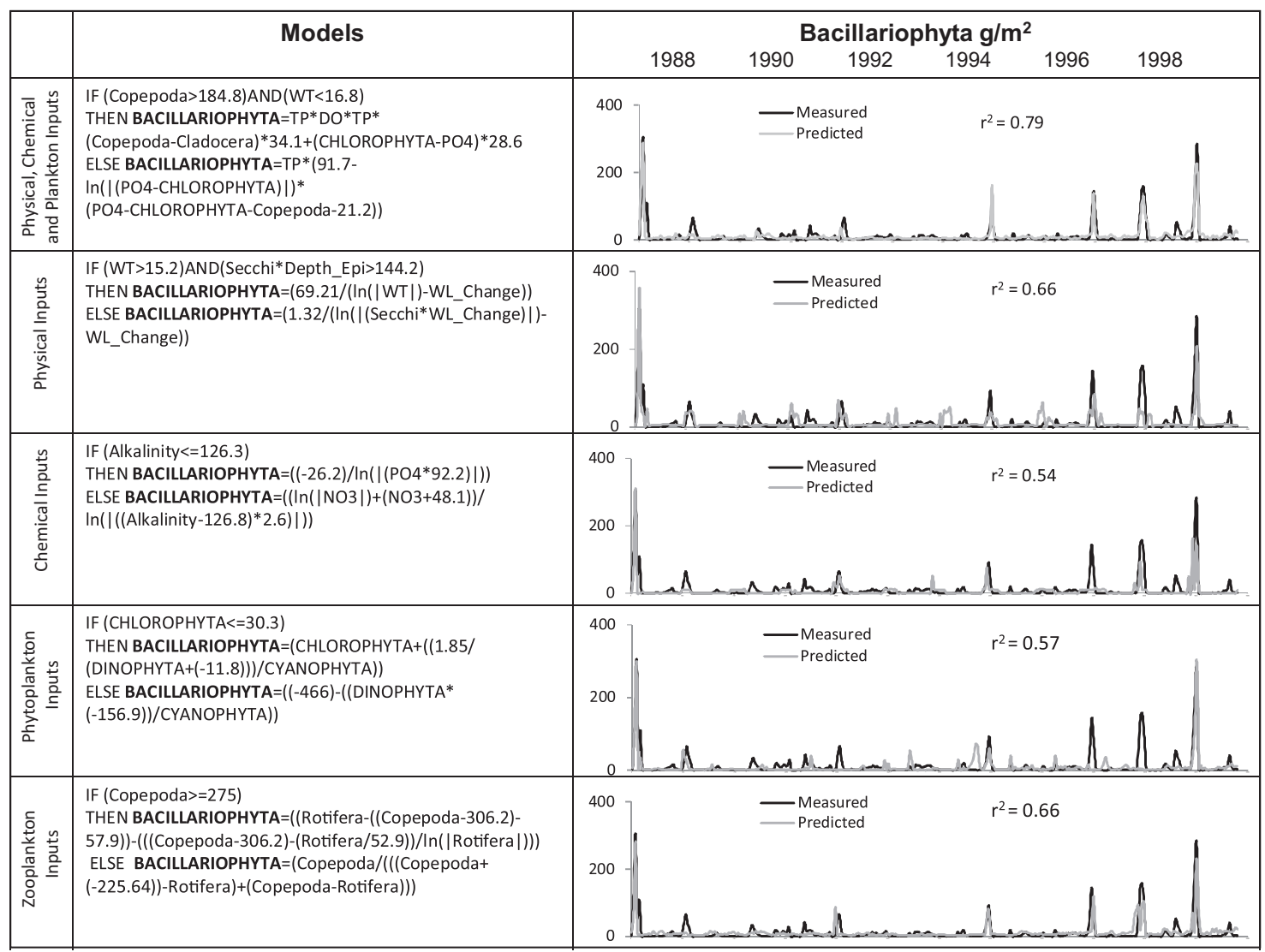

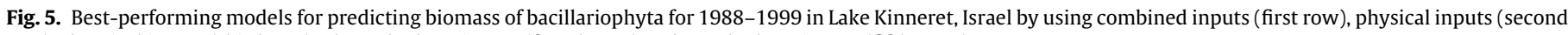
row), chemical inputs (third row), phytoplankton inputs (fourth row) and zooplankton inputs (fifths row). 


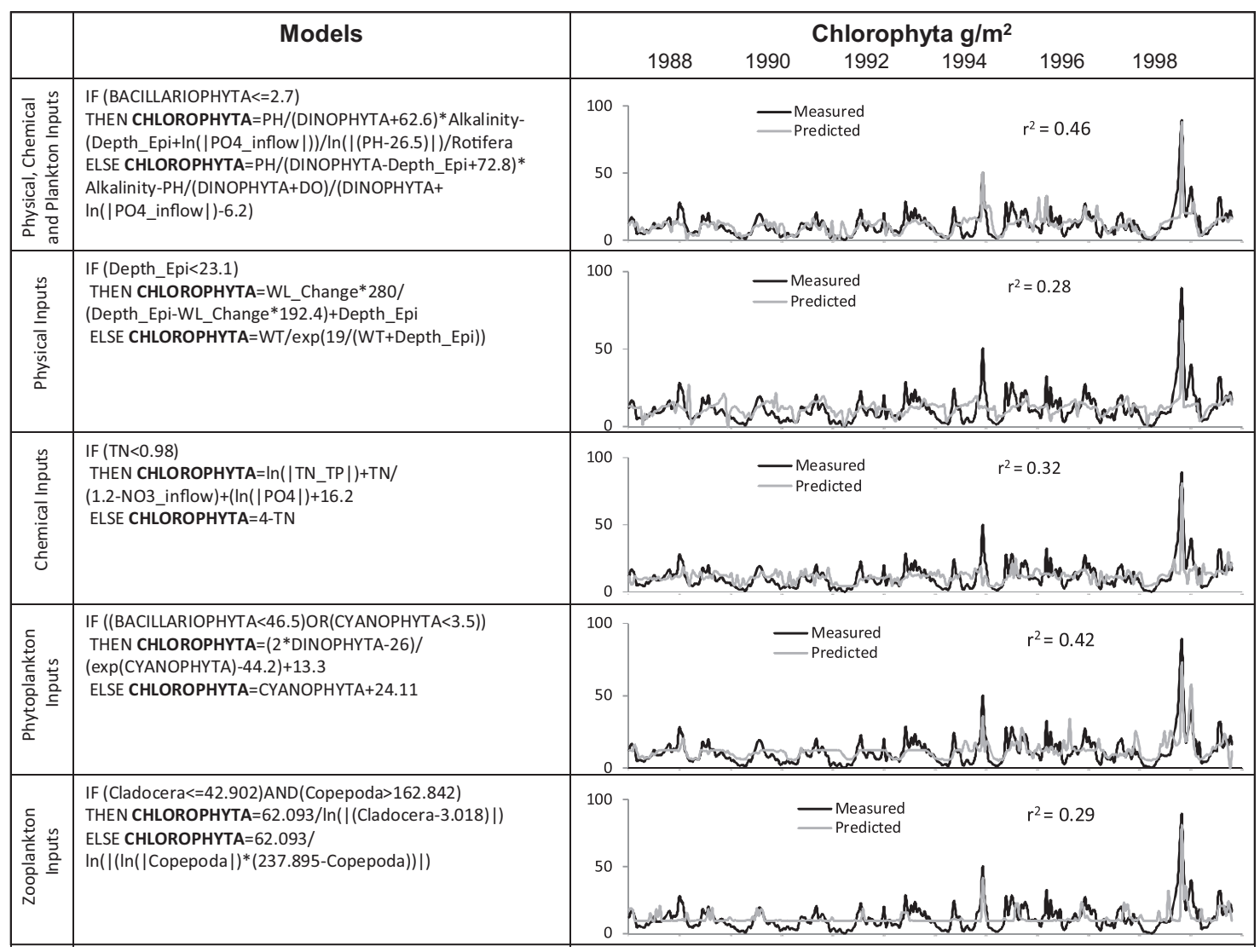

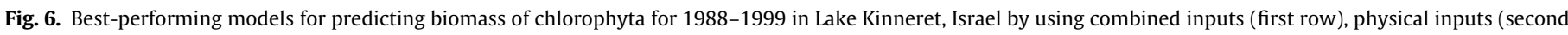
row), chemical inputs (third row), phytoplankton inputs (fourth row) and zooplankton inputs (fifths row).

based on functional groups that included predatory zooplankton (adult stages of the predatory copepods and predatory rotifers), herbivorous macro-zooplankton (cladocerans and copepodites) or micro-zooplankton (copepod nauplii, small herbivorous and bactivorous rotifers). Water level and inflow data were provided by the Israel Hydrological Service. Chemical analyses were performed by the Watershed Unit, Mekorot Water Company.

\subsection{Hybrid evolutionary algorithm HEA}

The research was conducted by means of the hybrid evolutionary algorithm HEA (Cao et al., 2006, in press) that has been previously successfully applied for predictive modeling of cyanobacteria growth for a variety of lake and rivers worldwide (e.g. Chan et al., 2007; Kim et al., 2007; Recknagel et al., 2008; Recknagel et al., submitted). It has been designed by combining genetic programming (GP) for optimizing the model structure and differential evolution (DE) for optimization of model parameters (see Fig. 1). GP is applied to search for the optimum model structure by recurrently recombining arithmetic and logic operators based on principles of crossover, mutation and reproduction as explained in great detail in Cao et al. (2006). The DE is an evolutionary algorithm designed for parameter optimization (Storn and Price, 1997) that extracts the differential information (i.e., distance and direction to global optimum) from the current population of solutions as guide to search for the global optimum. It, therefore, does not depend on additional probability distributions as common for conventional optimization algorithms but makes it a self-organizing scheme. According to Hrstka and Kucerová (2004) DE outperforms other optimization methods in terms of convergence speed and robustness.
HEA induces models from data patterns. It therefore requires cleansed and formatted cross-sectional or time-series data that are representative for the system to be modeled both in terms of number of observations and of relevance for the modeling purpose. The more representative data patterns are the more generic models become, and the more likely the model's predictive validity ranges beyond data limits. However ecosystem evolution requires that models become regularly revised by updated data.

The biweekly time series from 1988 to 1999 provided a wealth of seasonal and interannual patterns of abiotic and biotic limnological properties, but do not reflect patterns of the past 15 years. This may have lesser impact on results of inductive reasoning but prohibits hind- and forecasts of current plankton community dynamics based on these models.

In order to take full advantage of the information content of available data the boot-strap scheme has been implemented for the training of HEA as illustrated in Fig. 2. It randomly selects $r_{\max }$ datasubsets for training and testing for each of which $t_{\max }$ generations of models are evolved. After $r_{\max }$ boot-strap runs it determines the overall "fittest model" of all generations evolved by principles of genetic programming and differential evolution. The fitness of each model is evaluated by the root mean squared error (RMSE) between the measured training data $\hat{y}_{i}$ and the predicted data $y_{i}$ by the model defined as follows:

Fitness $=\sqrt{\frac{1}{k} \sum_{i=1}^{k}\left(\hat{y}_{i}-y_{i}\right)^{2}}$

This research applied $r_{\max }=100$ and $t_{\max }=80$ to all modeling experiments. 


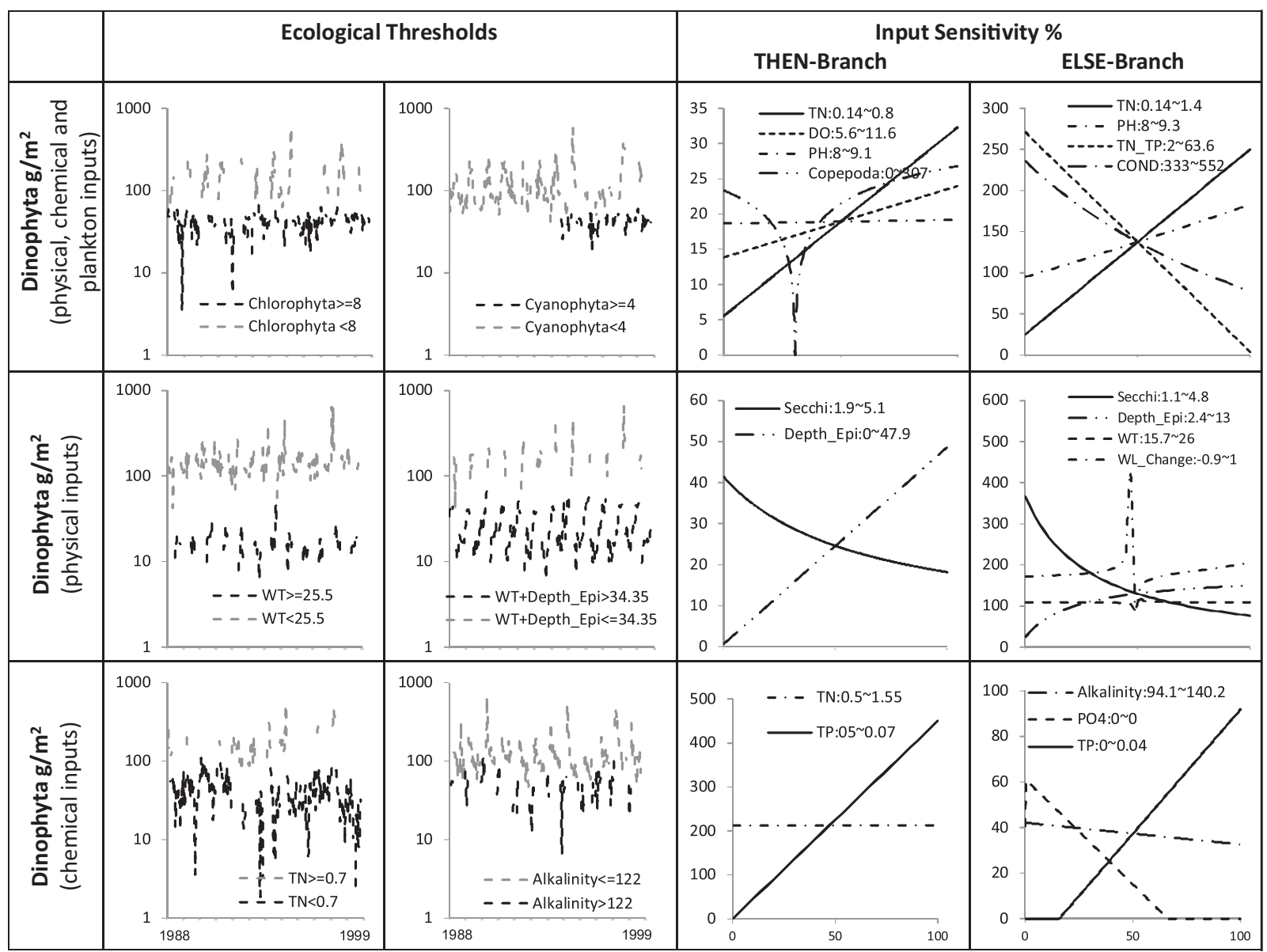

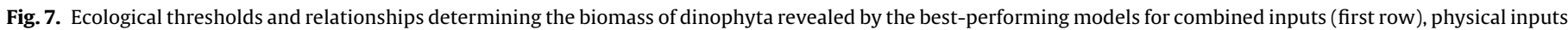
(second row) and chemical inputs (third row).

The software HEA automatically carries out sensitivity analyses for the input variables of each discovered model. It calculates output trajectories separately for each input range (mean \pm SD) by keeping remaining input variables constant at mean values. Resulting sensitivity curves visualize the output trajectories in percentage terms (0-100\%) within their range of each input.

\subsection{Wavelet analysis}

Wavelets facilitate spectrum analysis for non-stationary time series by performing a local time-scale decomposition of the signal, i.e., the estimation of its spectral characteristics as a function of time (Lau and Weng, 1995; Torrence and Compo, 1998). In this way it analyses how different scales relate to the periodic components of the signal change over time. These results are reflected by the wavelet cross-spectrum and wavelet coherency that allow revealing dependencies or relationships between two ecological variables respectively. Thus wavelet analysis appears to be well suited for the analysis of nonlinear and non-stationary ecological time series (Cazelles et al., 2008).

Two different episodes of dinophyta development from April to May in 1997 and 1998 were selected for this case study. Since diurnal or daily in situ measurements of limnological variables of lakes including plankton are worldwide still very rare, and were not available for this study of Lake Kinneret, we exemplarily applied the wavelet analysis by MATLAB to daily interpolated data of dinophyta and the variables $\mathrm{pH}$, Secchi depth, cyanophyta and rotifers.

\section{Results}

\subsection{Model validation}

Figs. 3-6 pinpoint the models with the best validation results for dinophyta, cyanophyta, bacillariophyta and chlorophyta using different input categories, such as physical, chemical and biological variables and their combination. The models are represented by IF-THEN-ELSE rules induced by HEA from a 12-year dataset. For all phytoplankton groups the best models were obtained from combined input of physical chemical and biological variables. The models for bacillariophyta (Fig. 3, top row) and dinophyta (Fig. 6, top row) achieved the highest coefficients of determination $\left(r^{2}\right)$ of 0.79 and 0.76 , respectively between computed and measured values. The visual comparison reaffirms the good validity of these two models by matching well the annual timing of exponential growth and peak magnitudes. Models based on physical inputs only achieved still good validation results for dino- (Fig. 3, 2nd row) and bacillariophyta (Fig. 6, 2nd row) with $r^{2}$ of 0.64 and 0.66 , respectively. The lowest $r^{2}$ value of 0.29 has been obtained by the dinophyta model using zooplankton variables as input (Fig. 3, bottom row) indicating that development of this algae does not depend on zooplankton abundance.

\subsection{Ecological relationships and thresholds}

Figs. 7 and 12 represent relationships between input variables and dinophyta separately for both the THEN- and ELSE-branches of the rule-based models in Fig. 3. In case of the dinophyta model 


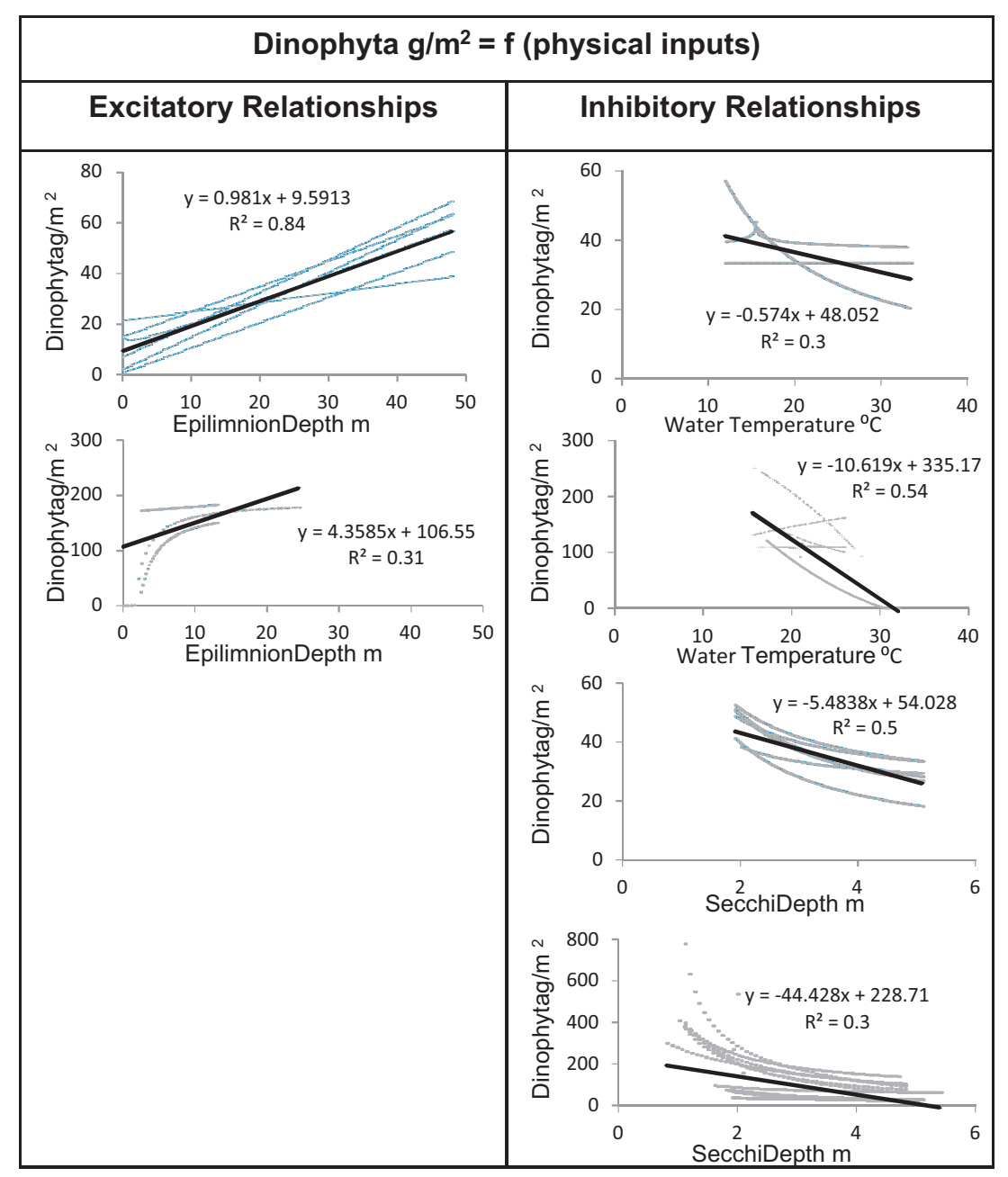

Fig. 8. Excitatory and inhibitory relationships of dinophyta with physical driving forces extracted from the 10 best-performing models for physical inputs. Linear trend lines are represented by solid black lines.

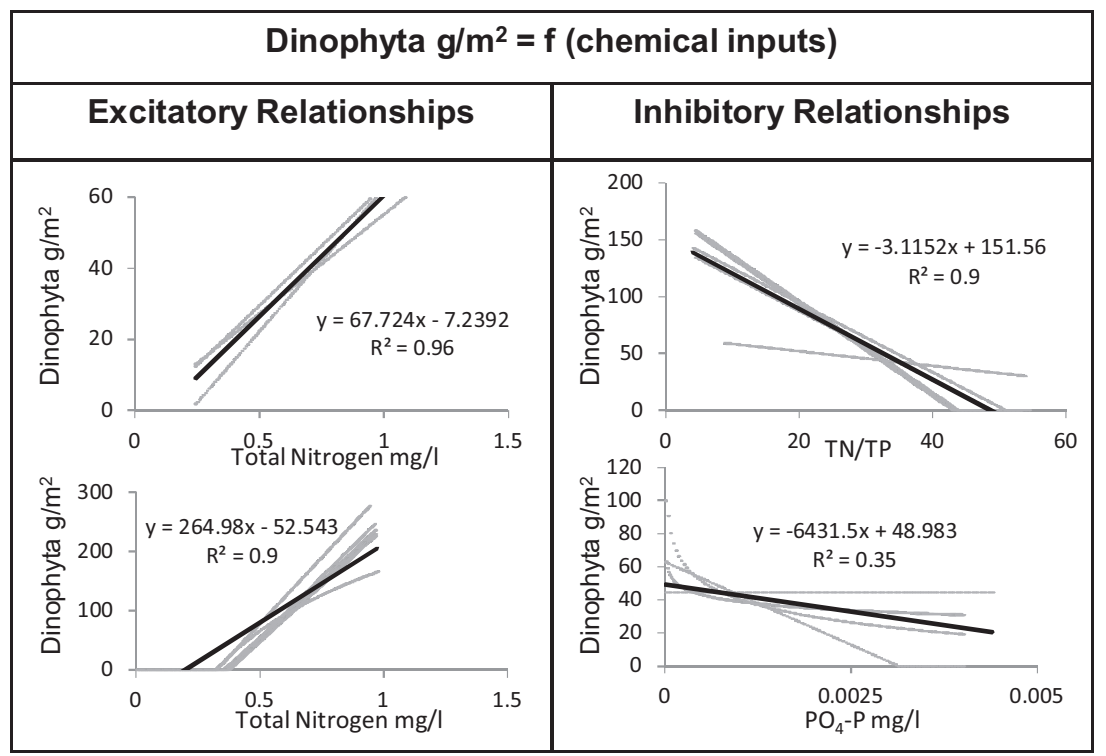

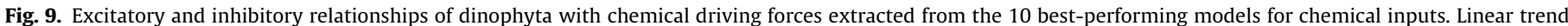
lines are represented by solid black lines. 


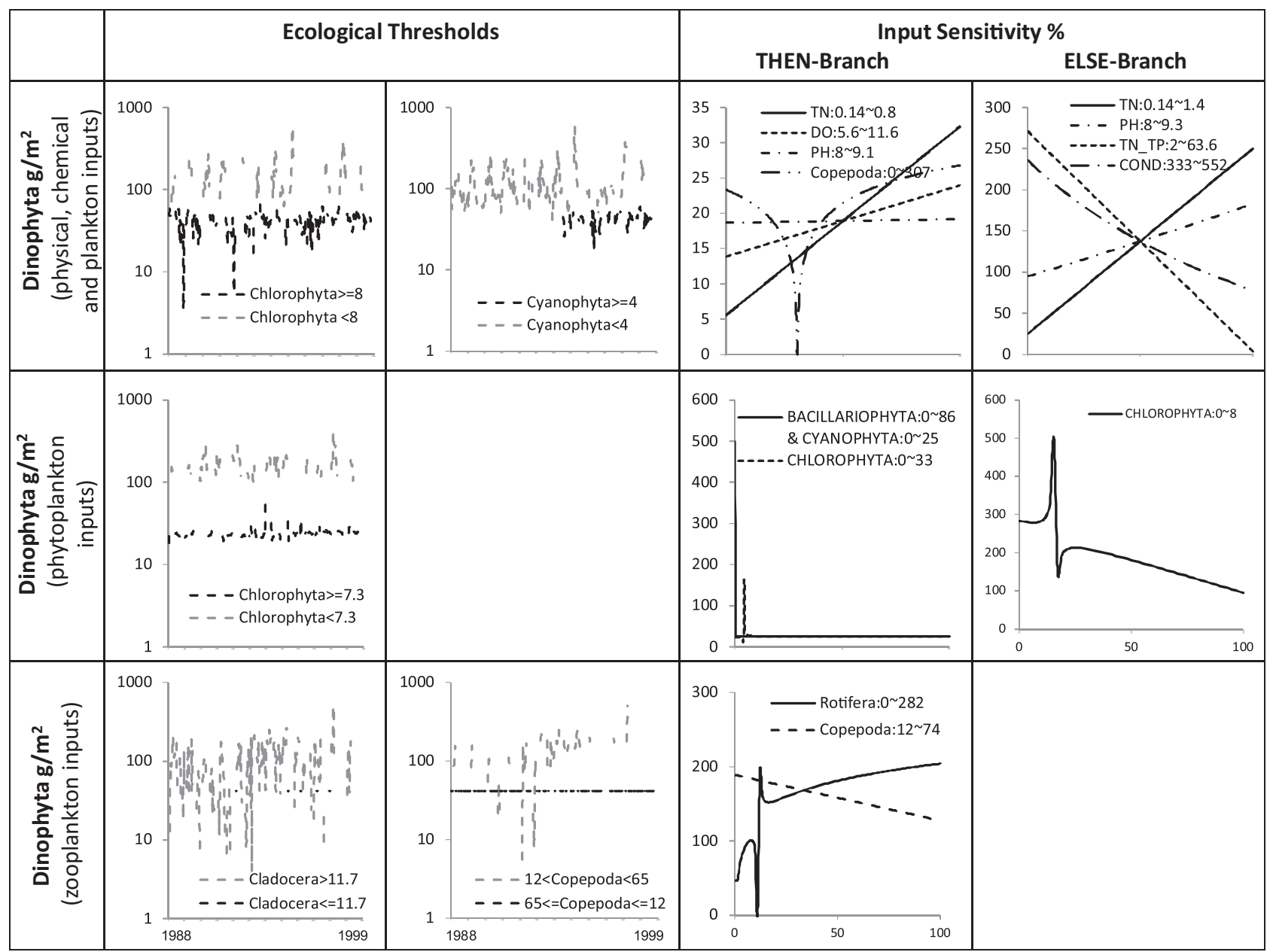

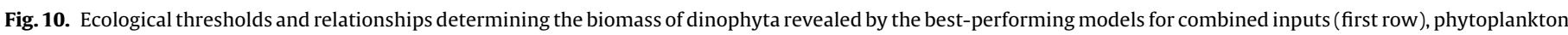
inputs (second row) and zooplankton inputs (third row).

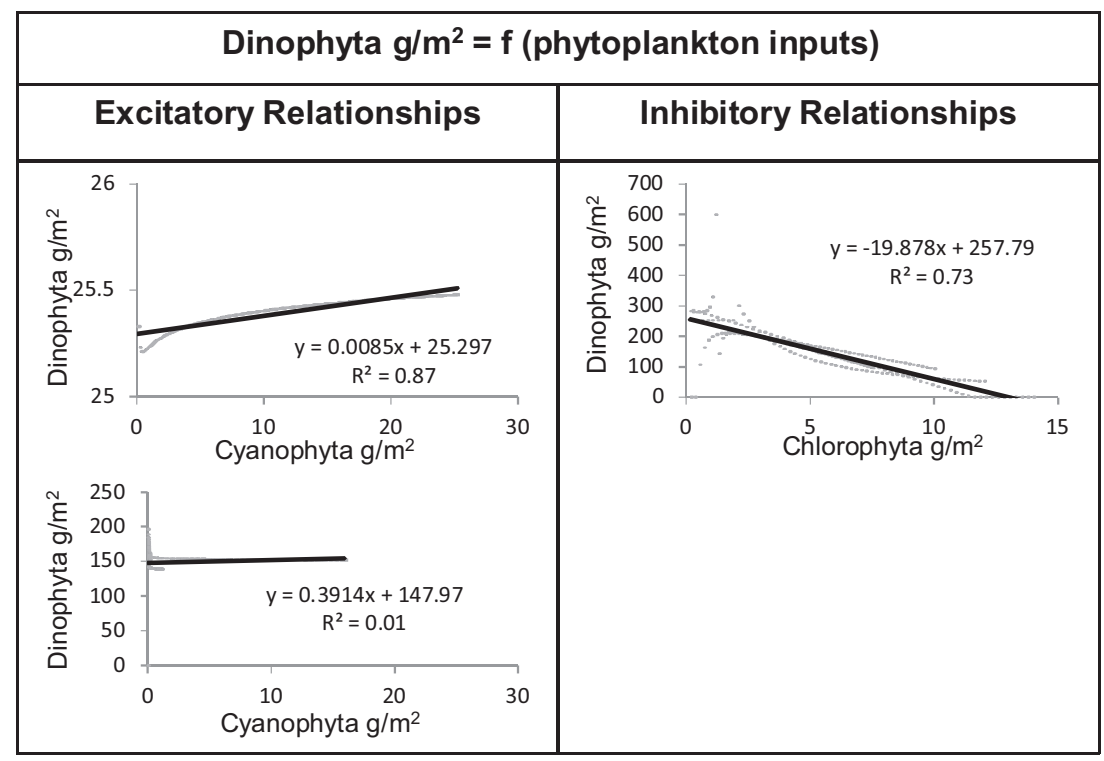

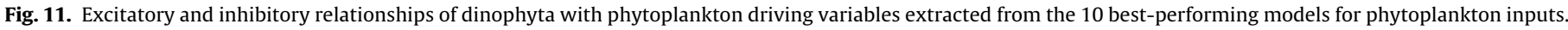
Linear trend lines are represented by solid black lines. 


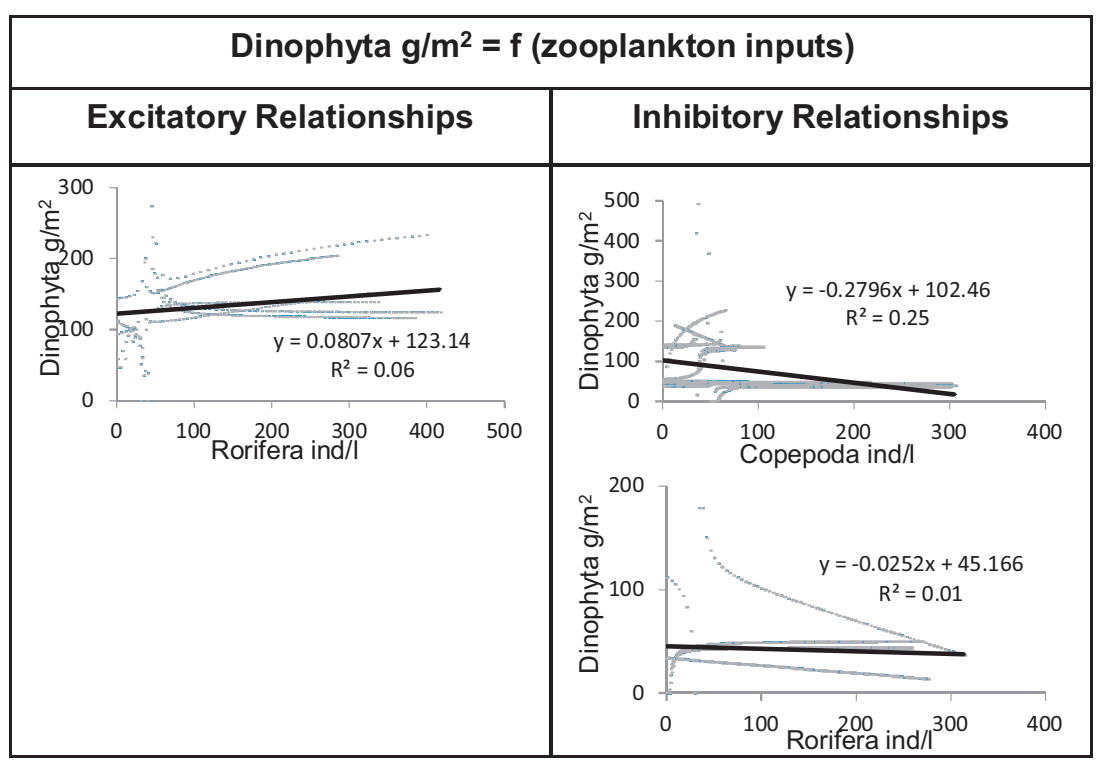

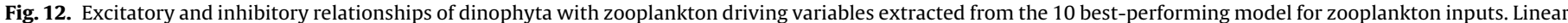
trend lines are represented by solid black lines.

obtained from combined input variables (Fig. 3, top row) the THEN-branch reflects conditions responsible for algae dynamics at relatively low biomass (up to $30 \mathrm{~g} / \mathrm{m}^{2}$ ) and the ELSE-branch for much higher biomasses (up to $300 \mathrm{~g} / \mathrm{m}^{2}$ ). Thresholds that triggered the THEN- and ELSE-branches were specified for chlorophyta $\left(<8 \mathrm{~g} / \mathrm{m}^{2}\right)$ and cyanophyta $\left(<4 \mathrm{~g} / \mathrm{m}^{2}\right)$ (Fig. 7 , top row). For both branches of the rule the total nitrogen (TN) served as dominating excitatory input variable whilst the ratio of total nitrogen to total phosphorus (TN/TP) seemed inhibitory affecting dinophyta biomass as indicated by the ELSE-branch of the model.

Alternative threshold conditions for water temperature (WT) $<25.5^{\circ} \mathrm{C}$ and the combination of WT and Depth_Epi were found to trigger the THEN- and ELSE-branches of the dinophyta model induced from physical inputs only (Fig. 3, 2nd row) by either predicting high or low biomass of dinophyta. The Secchi depth appears in the THEN- as well as the ELSE-branch as strong

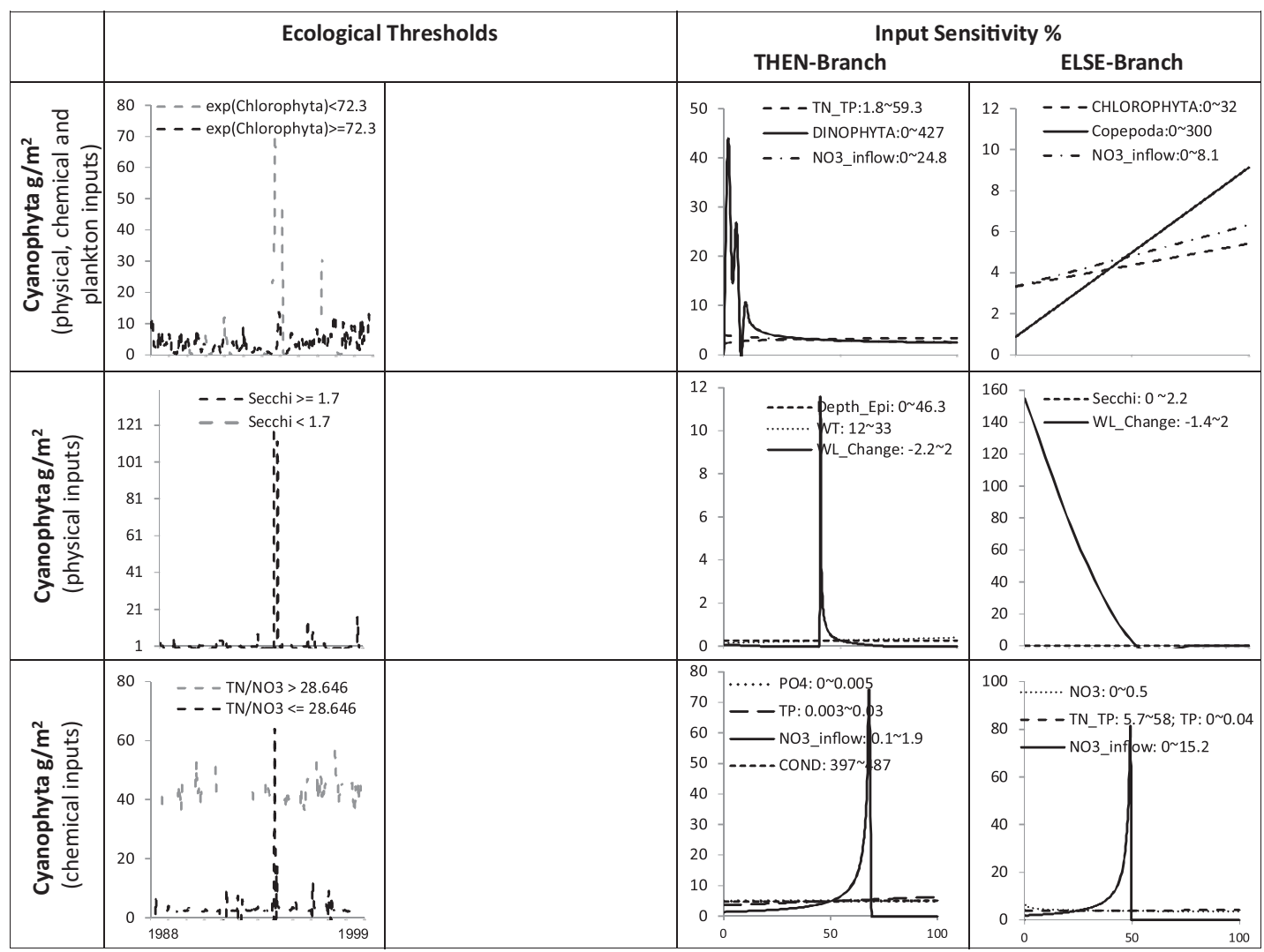

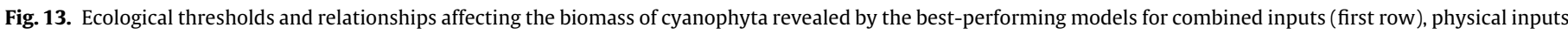
(second row) and chemical inputs (third row). 


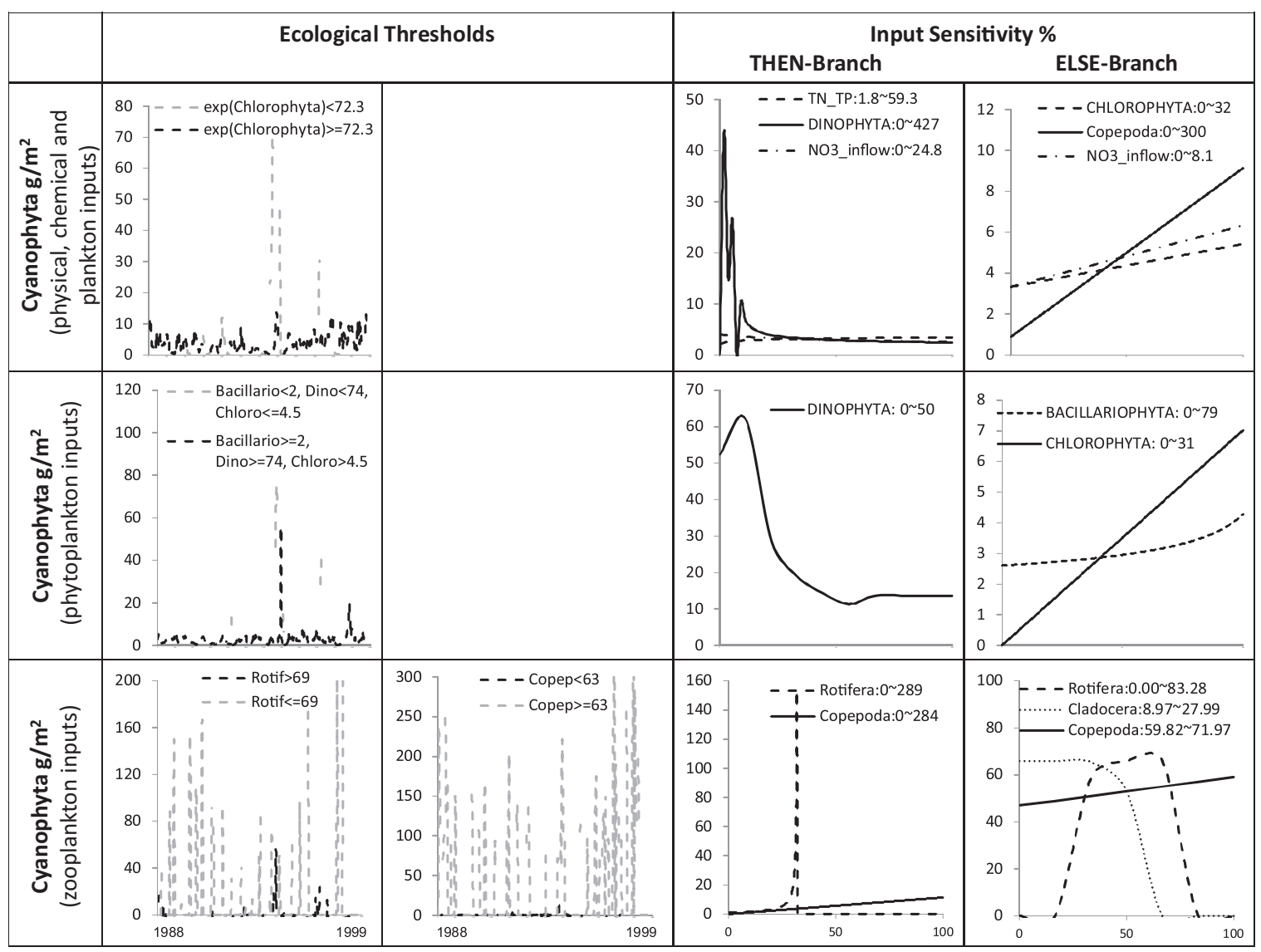

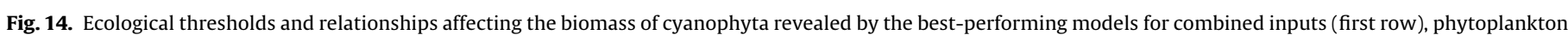
inputs (second row) and zooplankton inputs (third row).

inhibitory factor for the dinophyta development, whilst Depth_Epi excitatory affects both low and high dinophyta biomass. To generalize the relationships of dinophyta and physical inputs, sensitivity results of key input variables with highest $r^{2}$ have been extracted and correlated (see Fig. 8). These results reveal that epilimnion depth acts excitatory for low as well as high biomass of dinophyta in contrast to water temperature (WT) and Secchi depth that may inhibit dinophyta growth.

The threshold values for $\mathrm{TN}=0.7 \mathrm{mg} / \mathrm{L}$ and alkalinity $=122 \mathrm{mg} / \mathrm{L}$ of the model induced from chemical inputs only (Fig. 3, 3rd row) trigger either the THEN-branch for high or the ELSE-branch for low biomass of dinophyta. Fig. 9 indicates TN as key excitatory variable and $\mathrm{PO}_{4}$-P as well as TN/TP as inhibitory variables.

Ecological relationships and thresholds of dinophyta models induced from phyto- and zooplankton inputs (Fig. 3, 4th and 5th row) are represented in Fig. 10. The relationship between dinoand chlorophyta can be characterized as competitive exclusion highlighted both by the threshold of chlorophyta $=7 \mathrm{~g} / \mathrm{m}^{2}$ above which dinophyta tends to have low biomass and vice versa (Fig. 10, 2nd row). This finding corresponds well with the dinophyta model produced based on combined inputs where the threshold chlorophyta $=8 \mathrm{~g} / \mathrm{m}^{2}$ triggered high or low biomass of dinophyta as well (Fig. 10, 1st row), and is also supported by Fig. 11 highlighting chlorophyta as inhibitory factor. Fig. 11 also indicates a mutual relationship between cyanophyta and dinophyta.

The dinophyta model built from zooplankton inputs (Fig. 3, bottom row) does not show good correspondance to the observed data $\left(r^{2}=0.29\right)$. Therefore, the relationships obtained from sensitivity analysis might not be conclusive. However, Figs. 10 (bottom row) and 12 suggest inhibitory effects by copepods and a possibly weak mutual relationship between rotifers and dinophyta at high biomass.

Ecological relationships and thresholds extracted from five cyanophyta models (Fig. 4) are documented in Figs. 13 and 14. The model induced from combined inputs displays a strong inhibitory relationship between dino- and cyanophyta (Fig. 13, top row). The strongest excitatory relationship seems to come from copepods that may reflect eased competition pressure for cyanophyta by high grazing losses of other algal groups. The cyanophyta model induced from chemical variables suggests that a $\mathrm{TN} / \mathrm{NO}_{3}$-ratio > 28.6 usually triggers high cyanophyta biomass even though one peak event in 1994 seems to be associated with a TN/NO 3 -ratio $\leq 28.6$ (see Fig. 13 , bottom row).

Ecological relationships reflected by the cyanophyta model induced from phytoplankton inputs (Fig. 14, 2nd row) suggest that dinophyta is inhibited when cyanophyta reaches high biomass. Interestingly the results suggest mutual relationships of bacillariophyta and chlorophyta with cyanophyta when the latter has low biomass.

Figs. 15 and 16 illustrate the ecological relationships and thresholds determining the 5 models of bacillariophyta presented in Fig. 5 . The thresholds of the model induced from combined inputs confirm that bacillariophyta prefers cooler holomictic waters with WT $<17^{\circ} \mathrm{C}$ coinciding with a copepod abundance greater than $185 \mathrm{ind} / \mathrm{mL}$ (Fig. 15, top row) most likely dominated by nonherbivore adults but appear to be episodic for 1997-1999 rather regular.

The threshold of the bacillariophyta model induced from physical inputs (Fig. 15, 2nd row) highlights again the combination of low water temperature $\mathrm{WT} \leq 15.2^{\circ} \mathrm{C}$ and lake turnover - indicated by 


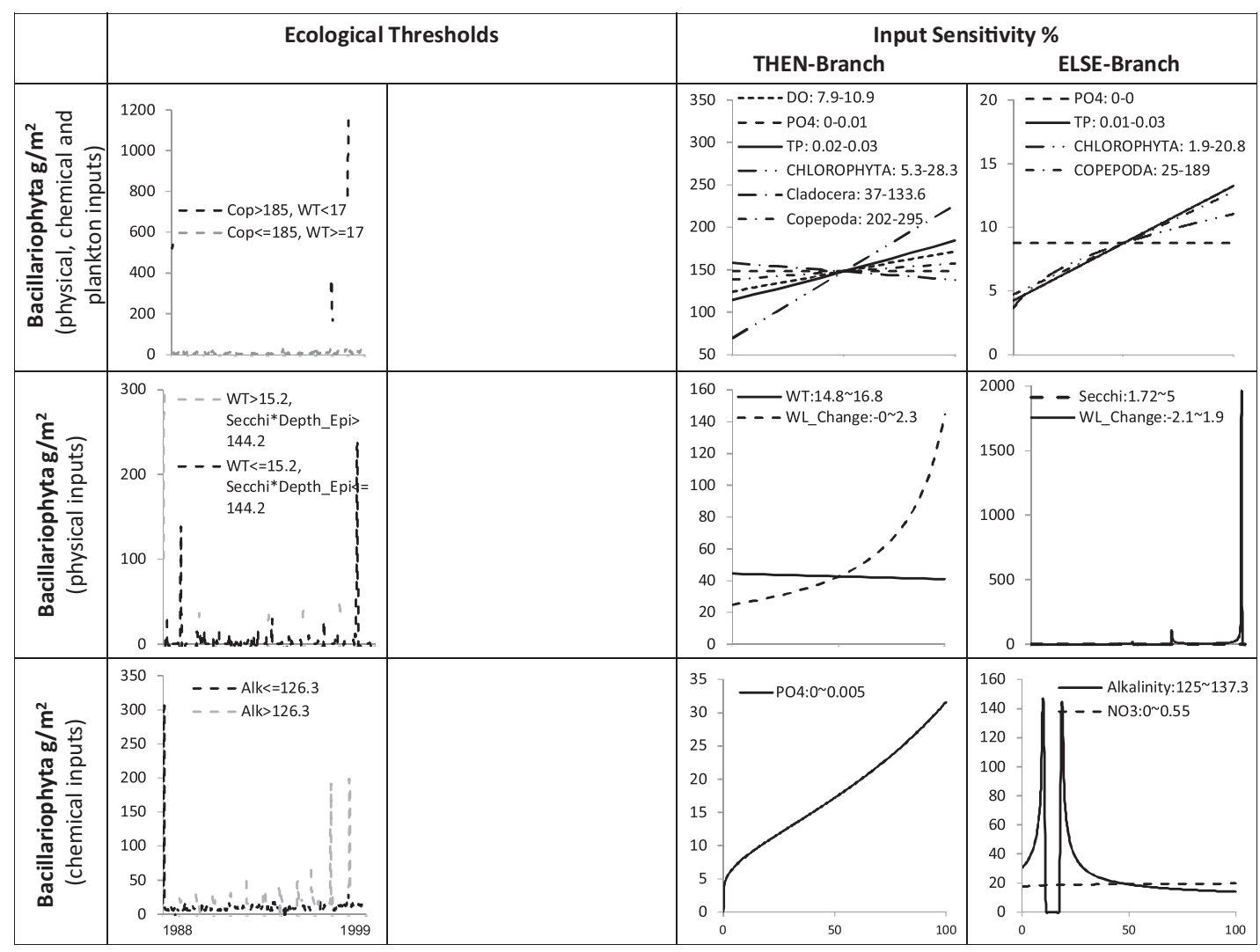

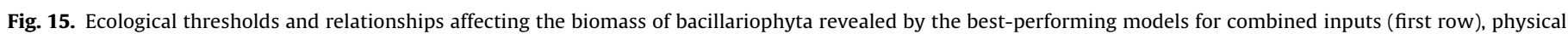
inputs (second row) and chemical inputs (third row).

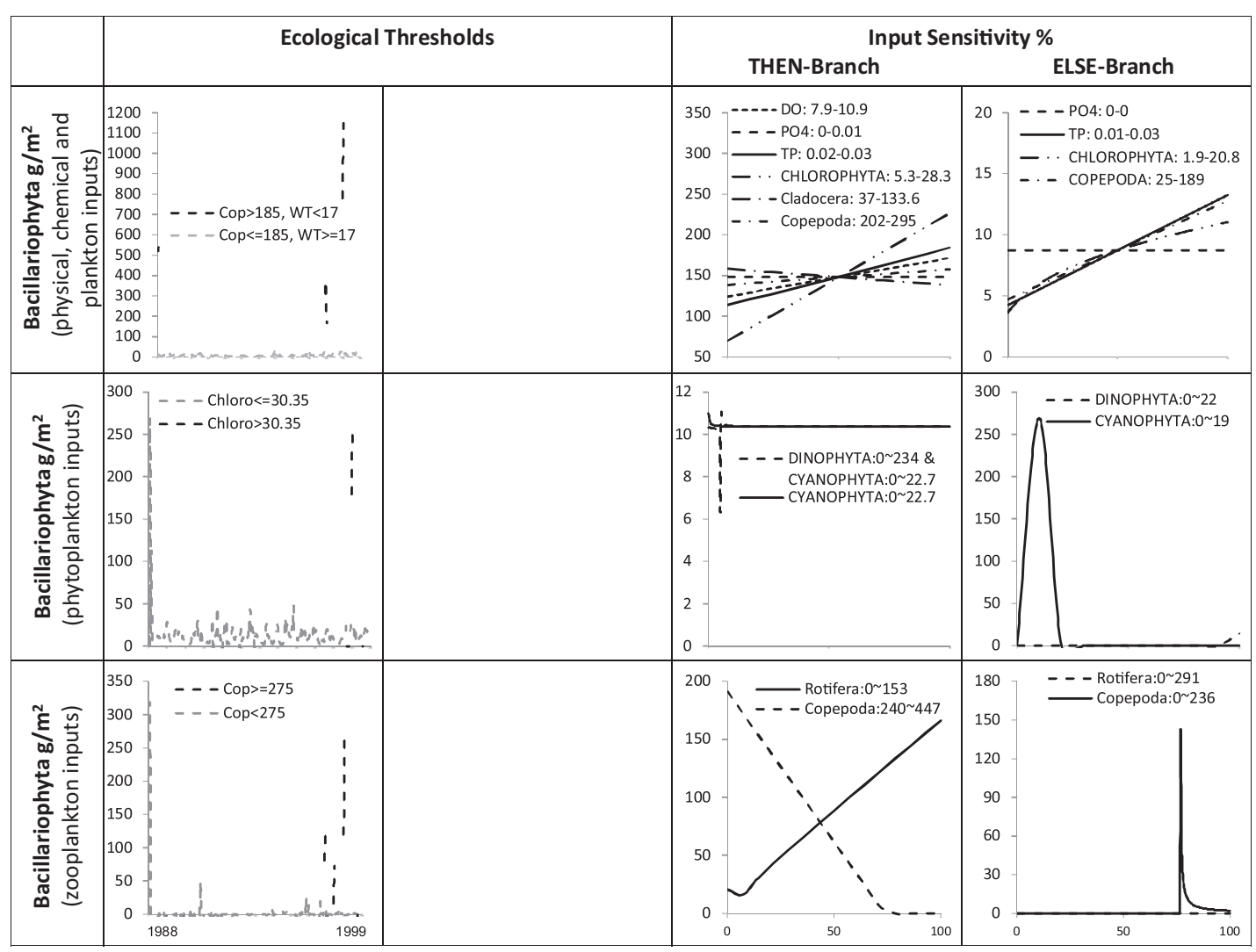

Fig. 16. Ecological thresholds and relationships affecting the biomass of bacillariophyta revealed by the best-performing models for combined inputs (first row), phytoplankton inputs (second row) and zooplankton inputs (third row). 


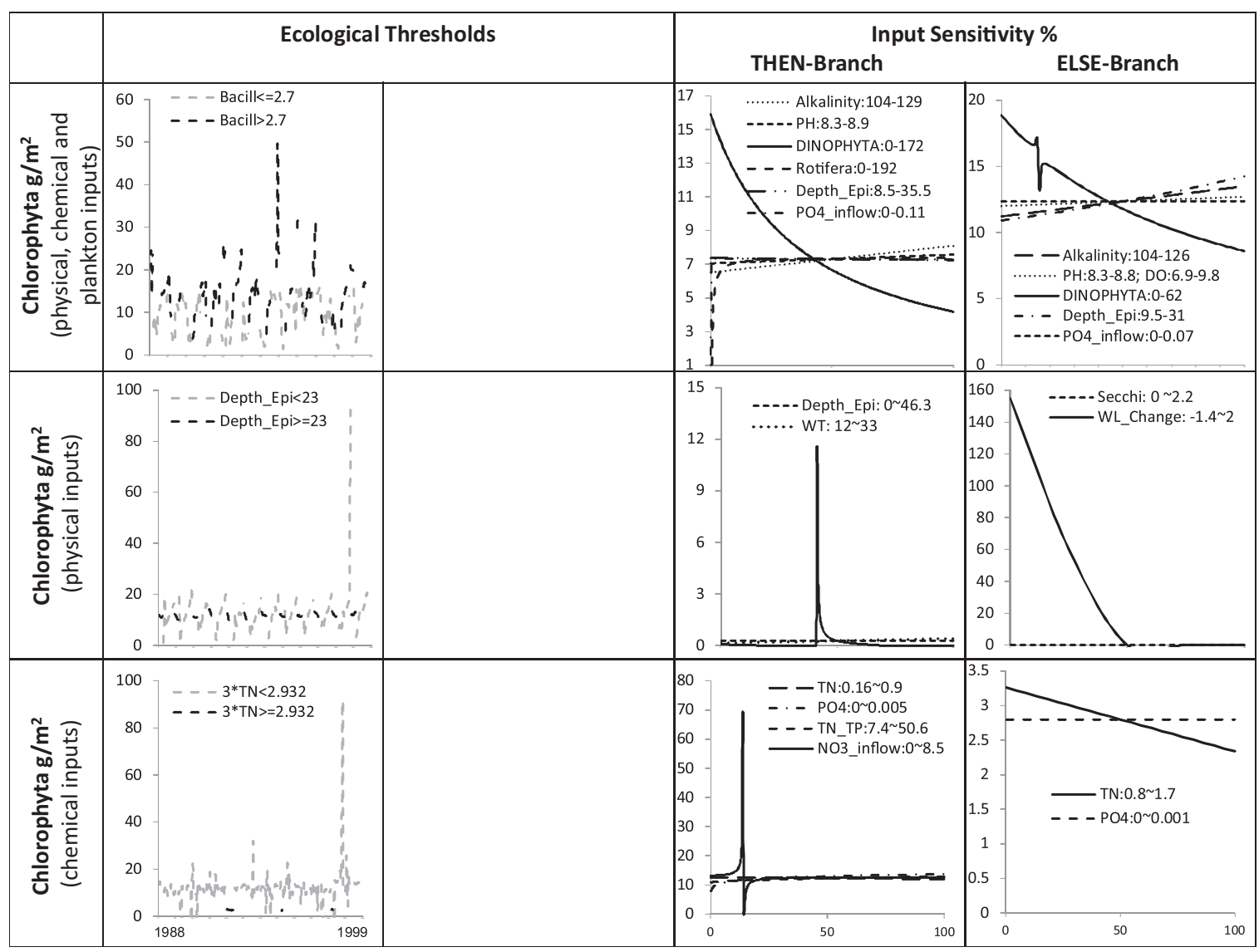

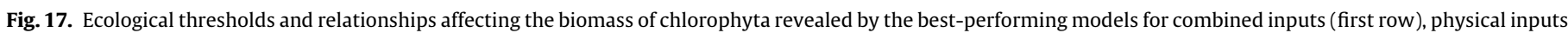
(second row) and chemical inputs (third row).

the high value of 144 for the product of Secchi depth and epilimnion depth - as criteria for highest bacillariophyta biomass.

Alkalinity appears to be a key variable affecting bacillariophyta in the model based on chemical inputs (Fig. 15, 3rd row) that may hint at limiting $\mathrm{CO}_{2}$ supply for photosynthesis. Competitive exclusion may seasonally emanate from chlorophyta for which a threshold of $30 \mathrm{~g} / \mathrm{cm}^{2}$ has been suggested by the model induced from phytoplankton inputs (Fig. 16, 2nd row) above which bacillariophyta tends to have low biomass.

The bacillariophyta model based on zooplankton again indicates episodic associations with copepods and rotifers. A copepod abundance of $275 \mathrm{ind} / \mathrm{L}$ appears as threshold for 1997-1999 beyond which high bacillariophyta biomass is triggered (Fig. 16, 3rd row).

Ecological relationships and thresholds considered in the chlorophyta models (Fig. 6) are summarized in Figs. 17 and 18. The model induced from combined inputs obtained the threshold value $2.7 \mathrm{~g} / \mathrm{m}^{2}$ for bacillariophyta above which high biomass of chlorophyta can be expected. This suggests that bacillariophyta and most likely non-motile chlorophyta coincide in winter and early spring.

A deep position of the thermocline at $23 \mathrm{~m}$ is considered as threshold for supporting high chlorophyta biomass in the model induced from solely physical inputs (Fig. 17, 2nd row).

Total nitrogen (TN) seems to greatly influence the growth of chlorophyta as it can be seen from the model induced from chemical inputs only (Fig. 17, 3rd row). It indicates that at times of fastest chlorophyta growth TN concentrations are drastically lowered.

The use of phytoplankton inputs resulted in a chlorophyta model with an $r^{2}=0.42$ that may not provide conclusive relationships. However it indicates that below the threshold of $4 \mathrm{~g} / \mathrm{m}^{2}$ for cyanophyta high chlorophyta biomass can be expected. This suggests possible competitive relationships between these two phytoplankton groups. The sensitivity analysis (Fig. 18, 2nd row) displays possible mutualism between chloro- and dinophyta.

The sensitivity analysis of the chlorophyta model induced from zooplankton inputs displays that highest biomass of chlorophyta occurs in the absence of cladocera (Fig. 18, 3rd row) implying its strong grazing pressure on chlorophyta. In contrast copepods appears to be in a rather mutual relationship with chlorophyta.

\subsection{Ecological lag times}

Two consecutive episodes of dinophyta development in Lake Kinneret were selected to test wavelets' capability to analyze time lags of dinophyta response to water quality properties. In April-May 1997 the dinophyta biomass remained at very low level of $10-20 \mathrm{~g} / \mathrm{m}^{2}$ with moderate interrelational response to water quality properties (Figs. 19a-22a). By contrast in April-May 1998 dinophyta biomass peaked to $400-500 \mathrm{~g} / \mathrm{m}^{2}$ with distinct interrelational responses to water quality properties (Figs. 19b-22b).

Fig. 19 compares interrelationships of dinophyta and $\mathrm{pH}$ between 1997 and 1998. The $\mathrm{pH}$ values reflect concentrations of dissolved $\mathrm{CO}_{2}$ affected by photosynthetic consumption of autotrophs. Alkaline conditions in 1997 (Fig. 19a) indicate that no freely available dissolved $\mathrm{CO}_{2}$ remained in the lake water resulting in a low wavelet coherence (correlation) between dinophyta and pH (Fig. 19b). In 1998 dinophyta reached an one-orderof-magnitude higher biomass concentration than in 1997, and strongly interrelated with $\mathrm{pH}$ (Fig. 19c). As a result high wavelet coherences are shown in Fig. 19d for days 20-35 in the 8 days periodic band and for days 35-45 in the 6 days periodic band. The phases in the 8 days periodic band are visualized in Fig. 19e 


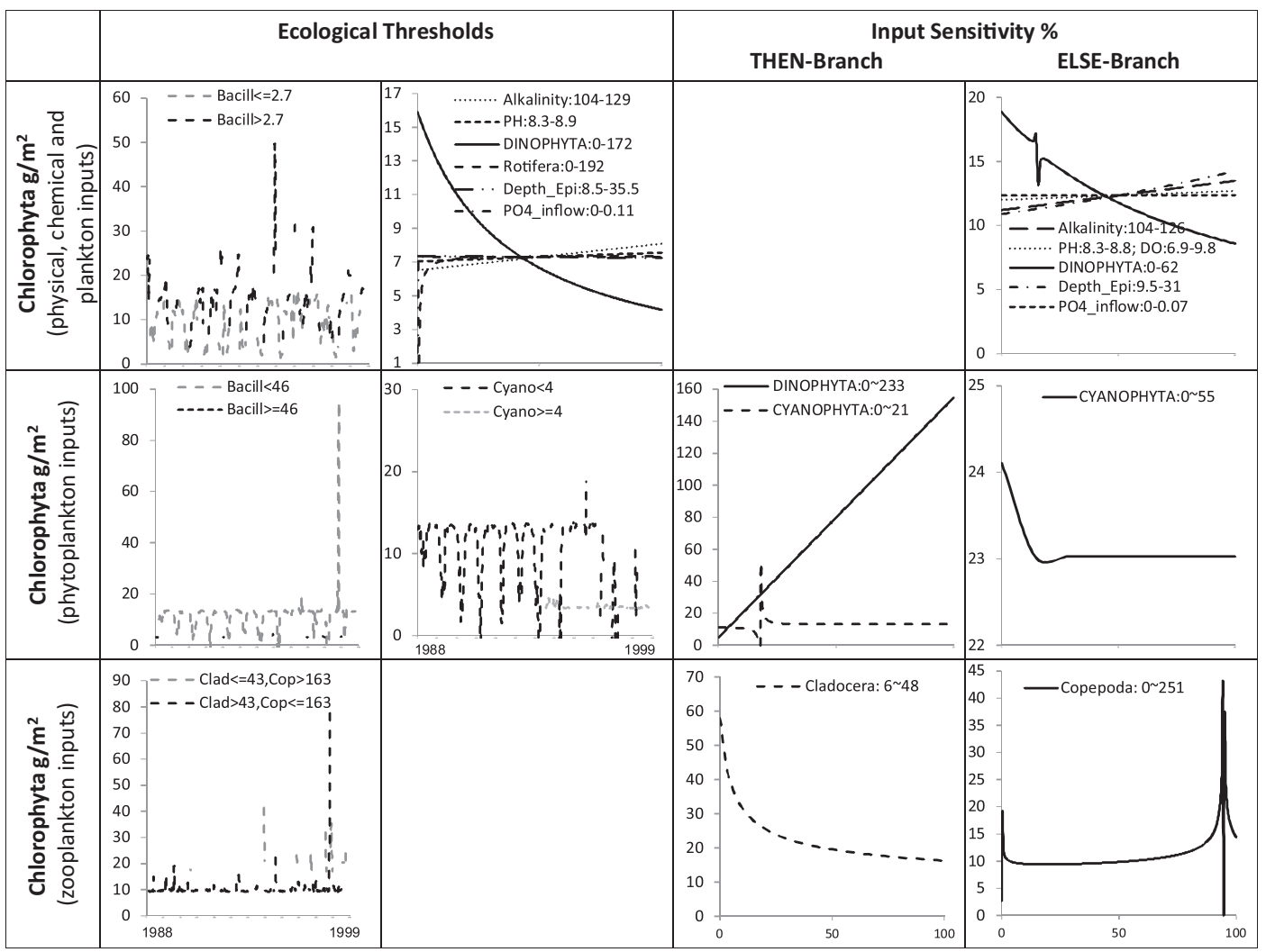

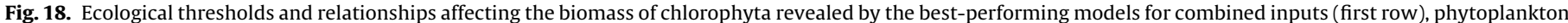
inputs (second row) and zooplankton inputs (third row).
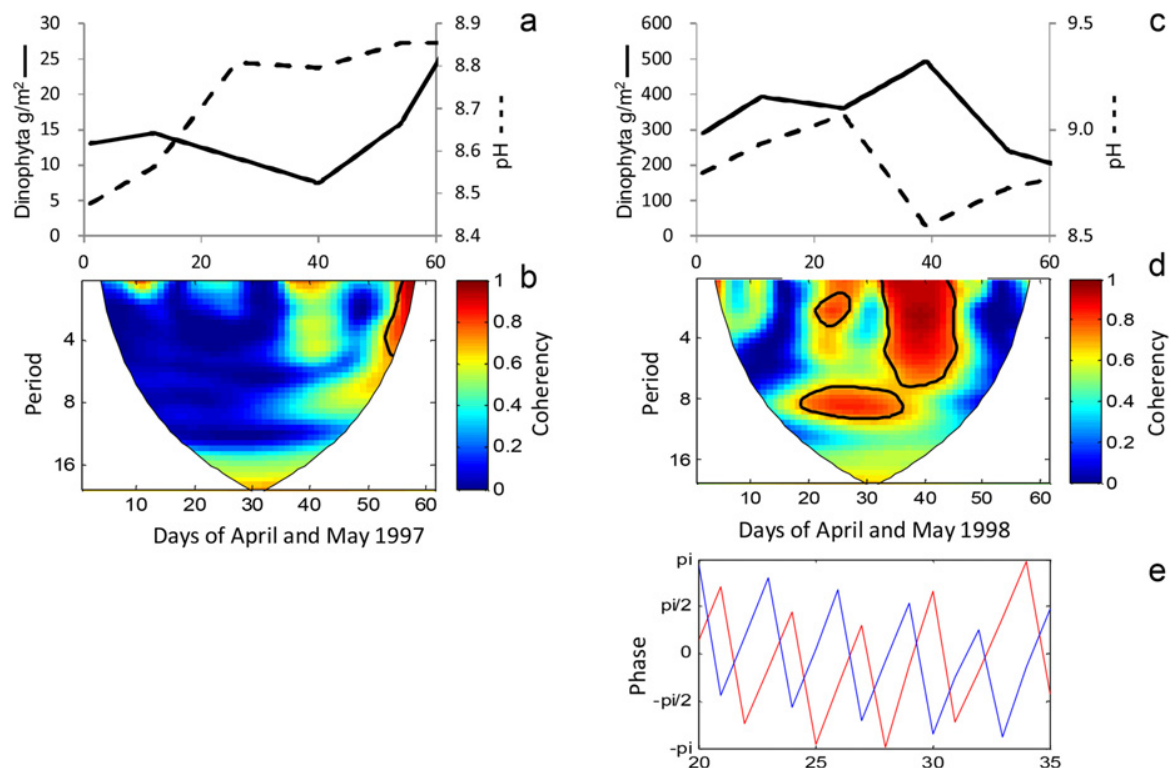

e

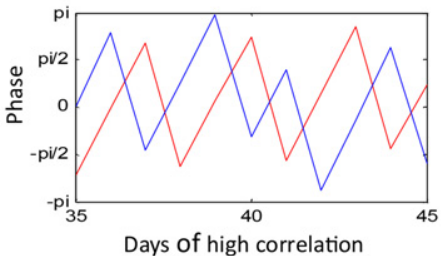

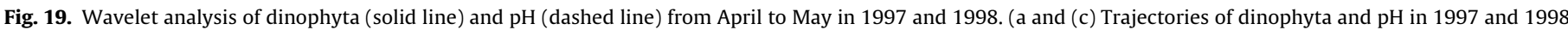

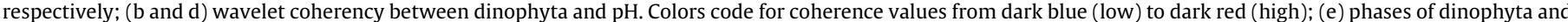

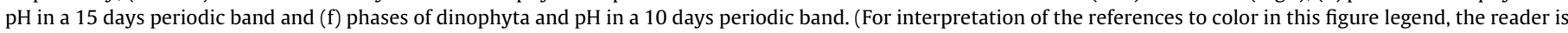
referred to the web version of the article.) 

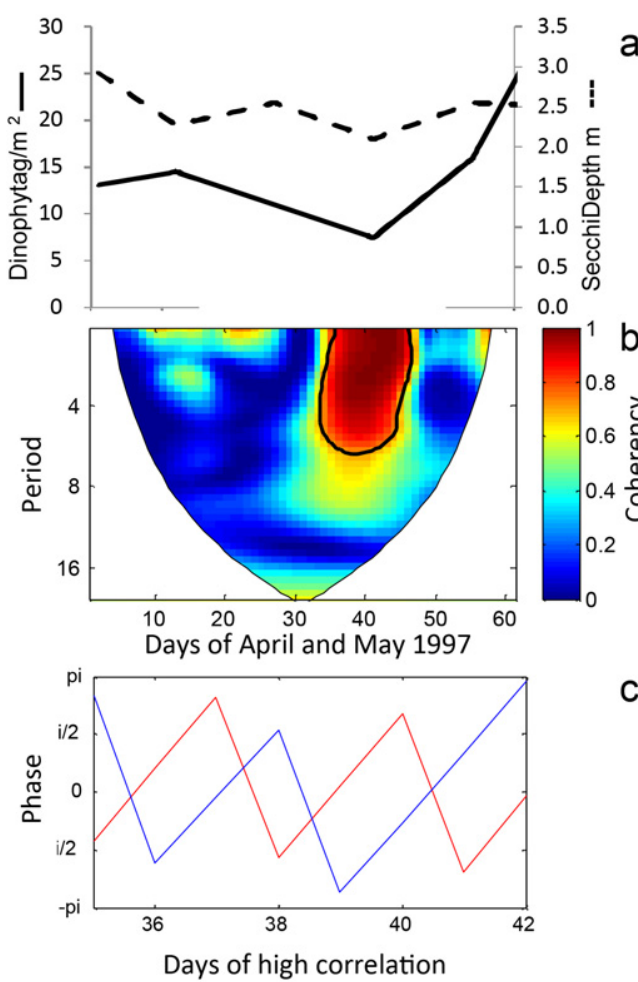

C
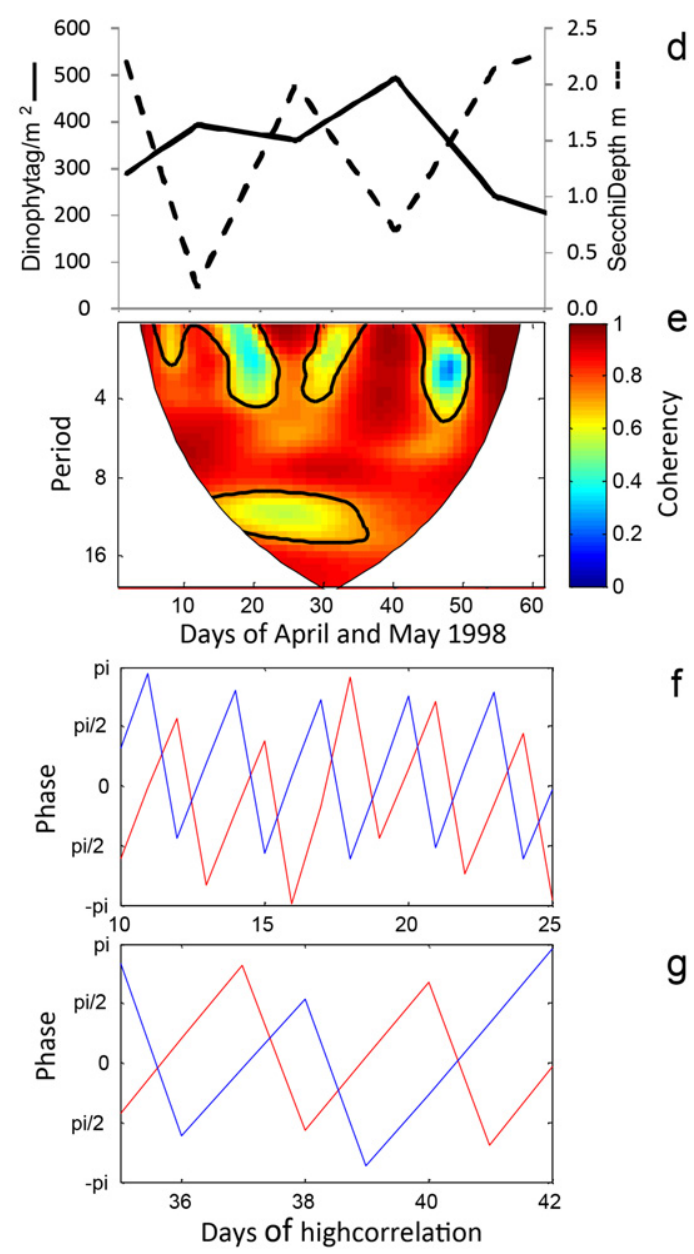

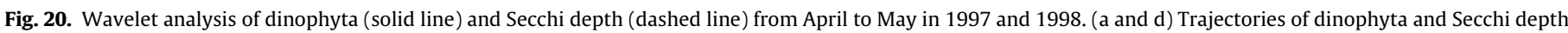

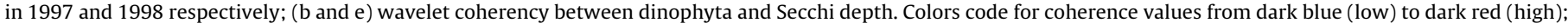

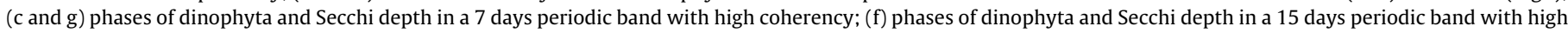
coherency. (For interpretation of the references to color in this figure legend, the reader is referred to the web version of the article.)

indicating a delay of 3 days and in the 6 days periodic band a delay of 2 days.

Fig. 20 compares interrelationships of dinophyta and water transparency measured as Secchi depth (SD) between 1997 and 1998. During April and May in 1997 the SD fluctuates between 2.2 and $3 \mathrm{~m}$ whereby dinophyta biomass remains at relative low level of $10-28 \mathrm{~g} / \mathrm{cm}^{2}$ (Fig. 20a). During 7 days from day 35 both dinophyta and SD simultaneously decrease hinting at possible self-shading effects. This 7 days period is highlighted by high wavelet coherence between dinophyta and SD in the 6 days periodic band (Fig. 20b) and corresponding phases in Fig. 20c indicate a delay of 3 days. By contrast the 60 days in April and May in 1998 are characterized by consistently strong interrelationships between dinophyta and SD suggesting self-shading effects of dinophyta whereby high biomass events in the range of $300-500 \mathrm{~g} / \mathrm{m}^{2}$ correspond with plunging SD (Fig. 20d). High wavelet coherences are shown for the 60 days in Fig. 20e with highest values for days $10-25$ in the 8 days periodic band and for days 35-42 in the 6 days periodic band. The phases in the 8 days periodic band are visualized in Fig. $20 \mathrm{f}$ indicating a delay of 4 days and phases in the 6 days periodic band (Fig. 20g) suggest a delay of 3 days.

Fig. 21a shows that cyanophyta biomass is steadily growing up to $40 \mathrm{~g} / \mathrm{m}^{2}$ coinciding with dinophyta decreasing to a level of $10 \mathrm{~g} / \mathrm{m}^{2}$ in May 1997. A 7 days period from day 35 appears with high wavelet coherence between dinophyta and cyanophyta in the 6 days periodic band (Fig. 21b) and the corresponding phase in
Fig. 21c suggests a delay of 3 days. The conditions look completely different in April and May 1998 when dinophyta remains at a high biomass of $200-500 \mathrm{~g} / \mathrm{m}^{2}$ most likely outcompeting cyanophyta (Fig. 21d). The corresponding wavelet coherence between dinophyta and cyanophyta in Fig. 21e is therefore insignificantly low.

Fig. 22a shows an almost synchronized occurrence of dinophyta and rotifers in the first 40 days of April-May in 1997 with dinophyta at low biomass level and rotifers with high individual numbers of up to $500 \mathrm{ind} / \mathrm{L}$. However the corresponding wavelet coherence between dinophyta and rotifers in Fig. 22b appears very low. By contrast high wavelet coherence is shown for the days 30-45 in 1998 (Fig. 22d) that reflects contrarily directed developments of dinophyta and rotifers during this period (Fig. 22c). The corresponding phase in the 6 days period phase (Fig. 22e) suggests a delay of 3 days.

\section{Discussion}

Good validation results have been achieved by models for bacillario- and dinophyta, respectively, whilst $r^{2}$ values for cyanophyta models scored lowest. Models based solely on zooplankton inputs scored in all these experiments lowest indicating that top-down control of algal biomass could have only secondary effect, whilst models that are based on combined effect of physical, chemical, phytoplankton and zooplankton inputs scored highest. Models based on physical inputs only achieved still good validation 


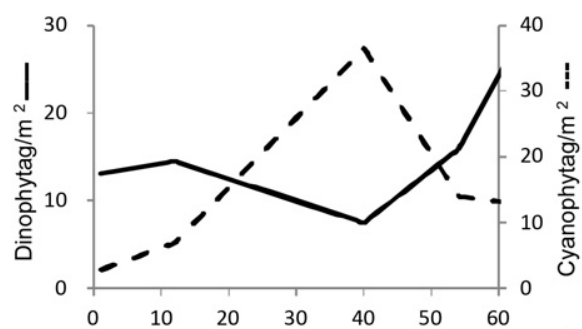

a

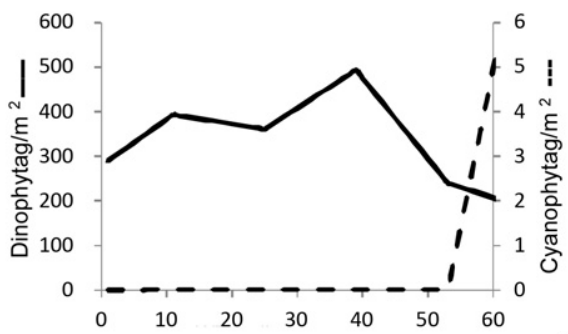

d
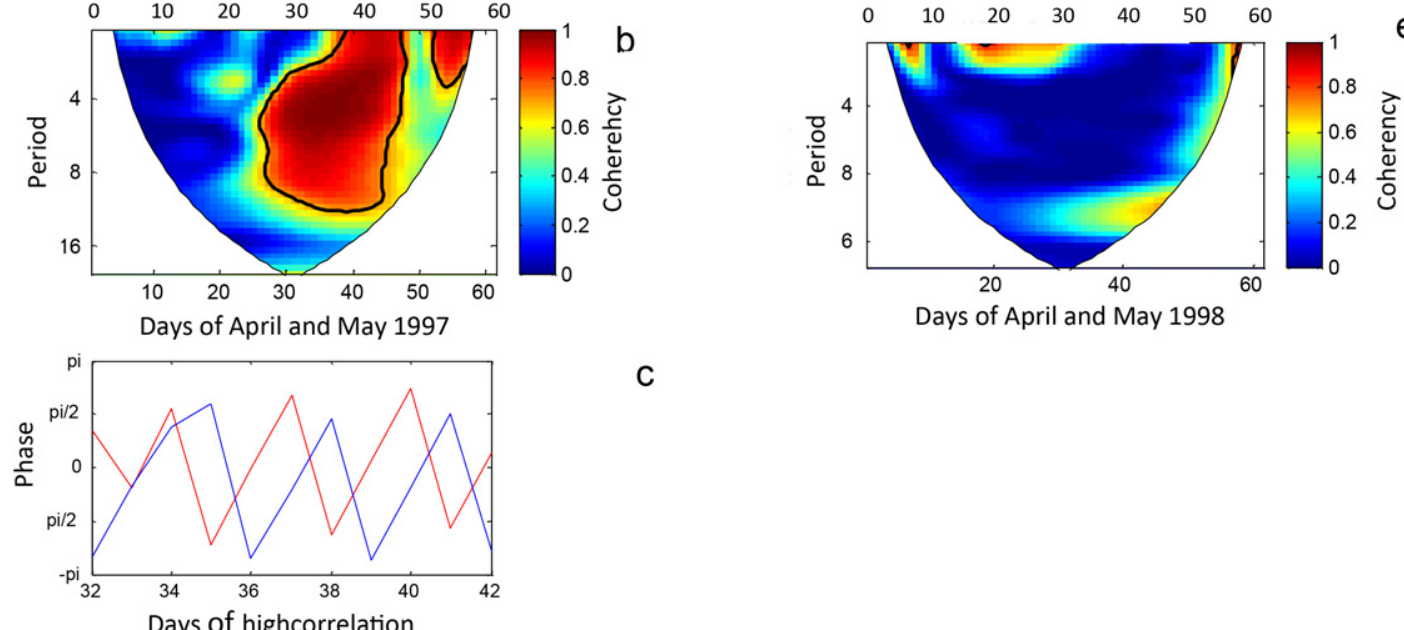

C

Fig. 21. Wavelet analysis of dinophyta (solid line) and cyanophyta (dashed line) from April to May in 1997 and 1998. (a and d) Trajectories of dinophyta and cyanophyta in 1997 and 1998 respectively; (b and e) wavelet coherency between dinophyta and cyanophyta. Colors code for coherence values from dark blue (low) to dark red (high); (c) phases of dinophyta and cyanophyta in a 11 days periodic band with high coherency. (For interpretation of the references to color in this figure legend, the reader is referred to the web version of the article.)

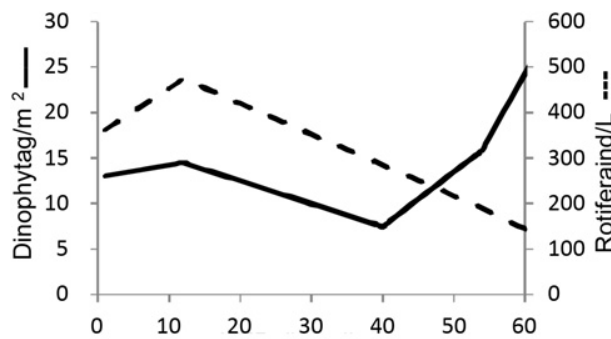

a
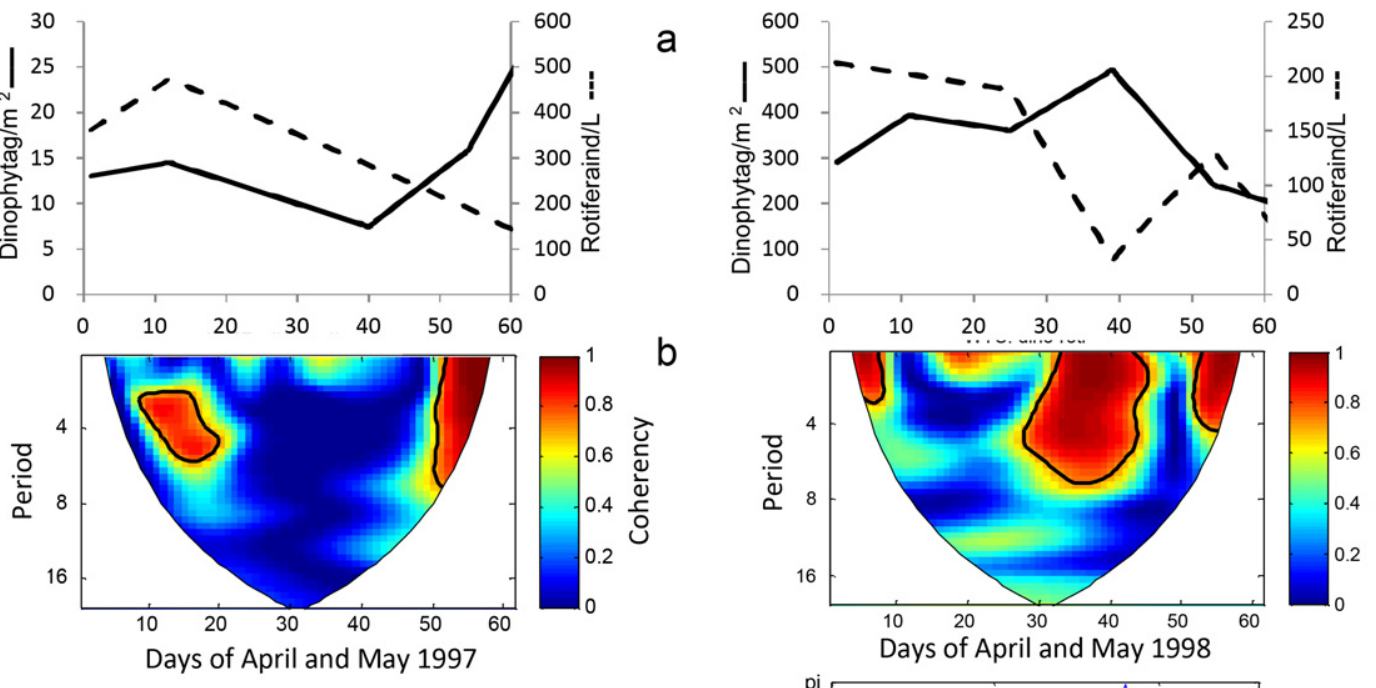

d

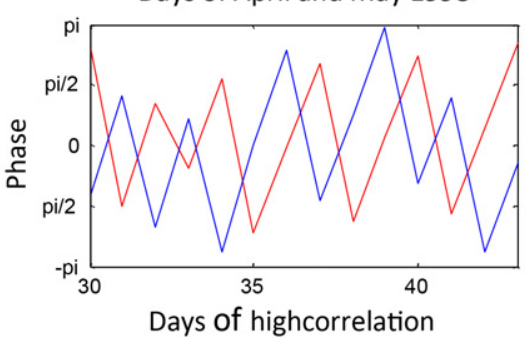

e

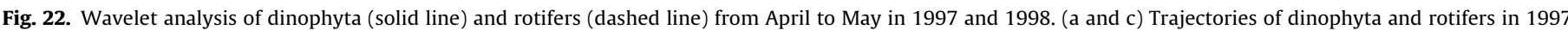

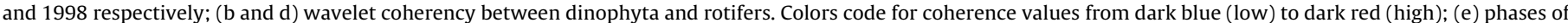

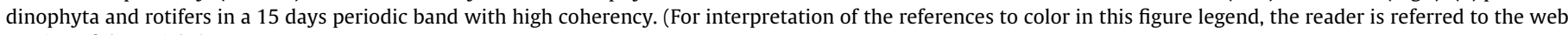
version of the article.) 
results by selecting such inputs as epilimnion depth (Depth_Epi) referring to motile algae favored by calm conditions during lake stratification or to diatoms favored by turbulent conditions during lake turnover (Yacobi and Ostrovsky, in press), and water level change (WL_Change) reflecting importance of inflow, which supplies limiting macro- or micronutrients.

Following ecological relationships and thresholds have been revealed by input sensitivity of models for the algal phyla:

(1) Dinophyta showed an excitatory relationship with epilimnion depth but inhibitory relationships with water temperature and Secchi depth suggesting benefits when competing with other algal groups during thermal stratification, and self-shading effects at times of high abundance. A water temperature of $25.5^{\circ} \mathrm{C}$ has been discovered as threshold above which the development of dinophyta biomass becomes inhibited. It may hint to the temperature threshold of the cost of having two flagella. As Berman-Frank et al. (1994) observed, unrestrained metabolism is susceptible to warming because at an increased temperature the supply of $\mathrm{CO}_{2}$ for photosynthesis in water to the cell surface is reduced. Therefore, warmer waters increase the rate at which resources are needed for both routine metabolism and for achieving maximum growth rate (Atkinson et al., 2003).

(2) Dinophyta showed an inhibitory relationship with $\mathrm{PO}_{4}-\mathrm{P}$ and TN/TP that hints to periods of phosphorus limitation as observed by Berman et al. (1995) in Lake Kinneret during winters.

(3) Dinophyta and cyanophyta interrelated by competitive exclusion corresponding with observations by Sukenik et al. (2002) that allelochemicals excreted by Microcystis severely inhibited the growth of Peridinium during its annual spring blooms in Lake Kinneret in the 1970s and 1980s.

(4) Dinophyta showed mutual relationships with rotifers and copepods.

(5) Bacillariophyta showed highest biomass at water temperatures below $17^{\circ} \mathrm{C}$ indicating its dependence on lake turnover in winter and spring for minimizing biomass losses by sedimentation (Reynolds, 1984; Yacobi and Ostrovsky, in press).

(6) Bacillariophyta responded seasonally different to abundant copepods suggesting that during winter and spring large bacillariophyta coexist mutually with seasonally dominant adult copepods but may experience grazing pressure by herbivorous juveniles of Mesocyclops oogunnus and Thermocyclops dybowskii during summer that feed preferably on small edible bacillariophyta as observed by Hambright et al. (2001).

Preliminary experiments with wavelets have demonstrated the potential of wavelets as tool for studying time lags between ecological attributes in non-stationary data sets. The results look realistic but are based on interpolated data. Possible bias by data interpolation can in future only be avoided by access to daily in situ data.

\section{Conclusions}

Ecology is rapidly changing from a data-limited to a data-rich science due to ongoing accumulation, sharing and integration of ecological data. Inductive reasoning of complex ecological data becomes a crucial source of ecological knowledge provided that multivariate nonlinear tools for data analysis and synthesis are available.

This study has demonstrated that evolutionary computation by HEA and spectrum analysis by wavelets have the capacity for inductive reasoning and forecasting of complex data of aquatic ecosystems. Ecological relationships and thresholds discovered in twelve years of data of Lake Kinneret were either in accordance with published knowledge about the lake or will be tested by further research. Improved understanding of the functioning of the Lake Kinneret ecosystem gained from this research will be considered in future reviews of lake monitoring programs, and taken into account for preventative control measures as well as early warning of mass developments of dinophyta such as Peridinium in Lake Kinneret.

\section{Acknowledgements}

We thank Maria Betânia Souza for valuable comments on the first draft of the manuscript. We also thank two anonymous reviewers for their critical comments that have significantly improved the manuscript. Our research was supported the Australian Research Council (Grant LP0990453) and the Lake Kinneret Monitoring Program funded by the Israel Water Authority.

\section{References}

APHA, 1998. Standard Methods for the Examination of Water and Wastewater. American Public Health Association, Washington, DC

Atkinson, D., Ciotti, B.J., Montagnes, D.J.S., 2003. Protists decrease in size linearly with temperature: ca. $2.5 \%{ }^{\circ} \mathrm{C}_{-} 1$. Proceedings of the Royal Society of London 270, 2605-2611.

Berman, T., Stone, L., Yakobi, Y.Z., Schlichter, M., Nishri, A., Pollingher, U., 1995. Primary production and phytoplankton in Lake Kinneret: a long term record (1972-1993). Limnology and Oceanography 40, 1064-1076.

Berman-Frank, I., Zohary, T., Erez, J., Dubinsky, Z., 1994. $\mathrm{CO}_{2}$ availability, carbon anhydrase, and the annual dinoflagellate bloom in Lake Kinneret. Limnology and Oceanography 39 (8), 1822-1834.

Cao, H., Recknagel, F., Welk, A., Kim, B., Takamura, N., 2006. Hybrid evolutionary algorithm for rule set discovery in time-series data to forecast and explain algal population dynamics in two lakes different in morphometry and eutrophication. In: Recknagel, F. (Ed.), Ecological Informatics. Scope, Techniques and Applications. , 2nd ed. Springer-Verlag, Berlin, Heidelberg/New York, pp. 330-342.

Cao, H., Recknagel, F., Orr, P. Enhanced functionality of the redesigned hybrid evolutionary algorithm HEA demonstrated by predictive modelling of algal growth in the Wivenhoe Reservoir, Queensland (Australia). Ecological Modelling, http://dx.doi.org/10.1016/j.ecolmodel.2012.09.009, in press.

Carpenter, St.R., Lathrop, R.C., 2008. Probabilistic estimate of a threshold for eutrophication. Ecosystems 11, 601-613.

Cazelles, B., Chavez, M., Berteaux, D., Meinard, F., Vik, J.O., Jenouvrier, St., Stenseth, N.C., 2008. Wavelet analysis of ecological time series. Oecologia 156, 287-304.

Chan, W.S., Recknagel, F., Cao, H., Park, H.-D., 2007. Elucidation and short-term forecasting of microcystin concentrations in Lake Suwa (Japan) by means of artificial neural networks and evolutionary algorithms. Water Research 41, 2247-2255.

Gophen, M., 1972. Zooplankton distribution in Lake Kinneret (Israel). Israel Journal of Zoology 21, 17-27.

Hambright, K.D., Zohary, T., Easton, J., Azoulay, B., Fishbein, T., 2001. Effects of zooplankton grazing and nutrients on the bloom-forming, $\mathrm{N}_{2}$-fixing cyanobacterium Aphanizomenon in Lake Kinneret. Journal of Plankton Research 23 (2), 165-174.

Holland, J.H., 1975. Adaptation in Natural and Artificial Systems. University of Michigan Press, Ann Arbour, MI.

Hrstka, O., Kucerová, A., 2004. Improvement of real coded genetic algorithm based on differential operators preventing premature convergence. Advance in Engineering Software 35, 237-246.

Kim, D.-K., Cao, H., Jeong, K.-S., Recknagel, F., Joo, G.-J., 2007. Predictive function and rules for population dynamics of Microcystis aeruginosa in the regulated Nakdong River (South Korea), discovered by evolutionary algorithms. Ecological Modelling 203, 147-156.

Lau, K.M., Weng, H., 1995. Climatic signal detection using wavelet transform: how to make a time series sing. Bulletin of the American Meteorological Society 76, 2391-2402.

Nishri, A., 2011. Long-term impacts of draining a watershed wetland on a downstream lake, Lake Kinneret, Israel. Air, Soil and Water Research 4, 57-70.

Ostrovsky, I., Rimmer, A., Yacobi, Y.Z., Nishri, A., Sukenik, A., Hadas, O., Zohary, T., 2013. Long-term changes in the Lake Kinneret ecosystem: the effects of climate change and anthropogenic factors. In: Goldman, C.R., Kumagai, M., Robarts, R.D. (Eds.), Climatic Change and Global Warming of Inland Waters: Impacts and Mitigation for Ecosystems and Societies. John Wiley \& Sons, New York, pp. 271-293.

Pollingher, U., 1986. Non-siliceous algae in a five meter core from Lake Kinneret (Israel). Hydrobiologia 143, 213-216.

Recknagel, F., Cao, H., van Ginkel, C., van der Molen, D., Park, H., Takamura, N., 2008. Adaptive agents for forecasting seasonal outbreaks of blue-green algal populations in lakes categorised by circulation type and trophic state. Verhandlungen der Internationalen Verein Limnologie 30 (2), 191-197. 
Recknagel, F., Orr, P., Cao, H. Inductive reasoning and forecasting of population dynamics of Cylindrospermopsis raciborskii in three sub-tropical reservoirs by evolutionary computation. Harmful Algae.(submitted).

Reynolds, C.S., 1984. The Ecology of Freshwater Phytoplankton. Cambridge University Press, NY, $384 \mathrm{pp}$.

Rimmer, A., Gal, G., Opher, T., Lechinsky, Y., Yacobi, Y.Z., 2011. Mechanisms of long-term variations of the thermal structure in a warm lake. Limnology and Oceanography 56, 974-988.

Rinaldi, S., Scheffer, M., 2000. Geometric analysis of ecological models with slow and fast processes. Ecosystems 3, 507-521.

Scheffer, M., Jeppesen, E., 2007. Regime shifts in shallow lakes. Ecosystems 10, 1-3.

Sonderegger, D.L., Wang, H., Clements, W.H., Noon, B.R., 2009. Using SiZer to detect thresholds in ecological data. Frontiers in Ecology and the Environment 7 (4), 190-195.

Storn, R., Price, K., 1997. Differential evolution--A simple and efficient heuristic for global optimization over continuous spaces. Journal of Global Optimization 11, 341-359.
Sukenik, A., Eshkol, R., Livne, A., Hadas, O., Rom, M., Tchernov, D., Vardi, A., Kaplan, A 2002. Inhibition of growth and photosynthesis of the dinoflagellate Peridinium gatunense by Microcystis sp. (cyanobacteria): a novel allelopathetic mechanism. Limnology and Oceanography 47 (6), 1656-1663.

Toms, J.D., Lesperance, M.L., 2003. Piecewise regression: a tool for identifying ecological thresholds. Ecology 84 (8), 2034-2041.

Torrence, C., Compo, G.P., 1998. A practical guide to wavelet analysis. Bulletin of the American Meteorological Society 79, 61-78.

Vasseur, D.A., Gaedke, U., 2007. Spectral analysis unmasks synchronous and compensatory dynamics in plankton communities. Ecology 88 (8), 2058-2071.

Yacobi, Y.Z., Ostrovsky, I. Sedimentation of phytoplankton: role of ambient conditions and life strategies of algae. Hydrobiologia, in press.

Zohary, T., 2004. Changes to the phytoplankton assemblage of Lake Kinneret after decades of predictable repetitive pattern. Freshwater Biology 49, 1355-1371.

Zohary, T., Ostrovsky, I., 2011. Ecological impacts of excessive water level fluctuations in stratified freshwater lakes. Inland Waters 1, 47-59. 